\title{
Sectoral Price Rigidity and Aggregate Dynamics*
}

\author{
Hafedh Bouakez ${ }^{\dagger} \quad$ Emanuela Cardia ${ }^{\ddagger} \quad$ Francisco J. Ruge-Murcia ${ }^{\S}$
}

February 2009

\begin{abstract}
In this paper, we study the macroeconomic implications of sectoral heterogeneity and, in particular, heterogeneity in price setting, through the lens of a highly disaggregated multisector model. The model incorporates several realistic features and is estimated using a mix of aggregate and sectoral U.S. data. The frequencies of price changes implied by our estimates are remarkably consistent with those reported in micro-based studies, especially for non-sale prices. The model is used to study $(i)$ the contribution of sectoral characteristics to the observed cross sectional heterogeneity in sectoral output and inflation responses to a monetary policy shock, (ii) the implications of sectoral price rigidity for aggregate output and inflation dynamics and for cost pass-through, and (iii) the role of sectoral shocks in explaining sectoral prices and quantities.
\end{abstract}

JEL Classification: E3, E4, E5

Keywords: Multi-sector models, price stickiness, simulated method of moments, sectoral shocks, monetary policy.

${ }^{*}$ Financial support from the Social Sciences and Humanities Research Council of Canada is gratefully acknowledged. Correspondence: Francisco J. Ruge-Murcia, Département de sciences économiques, Université de Montréal, C.P. 6128, succursale Centre-ville, Montréal (Québec) H3C 3J7, Canada. E-mail: francisco.rugemurcia@umontreal.ca.

${ }^{\dagger}$ HEC Montréal and CIRPÉE.

${ }^{\ddagger}$ Département de sciences économiques and CIREQ, University of Montréal.

${ }^{\S}$ Département de sciences économiques and CIREQ, University of Montréal. 


\section{Introduction}

There is now substantial evidence from studies based on micro data that the frequency of price adjustments differs significantly across goods. ${ }^{1}$ These studies also find that prices change relatively frequently, with a median duration between 1 and 3 quarters approximately. In contrast, standard sticky-price models assume identical price rigidity for all differentiated goods and, when estimated using aggregate data, usually imply larger price durations than found in the micro data. ${ }^{2}$

The contribution of this paper is threefold. First, we show that modelling explicitly sectoral heterogeneity in price rigidity and production technology can help reconcile macro models with the micro data. To that end, we construct and estimate a highly disaggregated multi-sector model where the sectors roughly correspond to the two-digit level of the Standard Industry Classification (SIC). Sectors differ in price rigidity, factor intensities and productivity shocks, and are interconnected through a roundabout production structure whereby they provide materials and investment inputs to each other following the actual Input-Output Matrix and Capital Flow Table of the U.S. economy. ${ }^{3}$ The model is estimated by the Simulated Method of Moments using a mix of aggregate and sectoral data and is shown to provide a reasonably accurate picture of the micro data. In particular, we find substantial heterogeneity in price rigidity across sectors and that the null hypothesis that prices are flexible cannot be rejected for 17 out of 30 sectors in our sample. Importantly, the frequencies of price changes implied by our estimates are generally consistent with micro-based estimates, especially for producer prices and regular consumer prices (excluding sales): the correlation between macro and micro estimates is around 0.5 and the price duration implied by our median estimate (1.5 quarters) is well within the range of durations reported in micro studies. Statistically, the null hypothesis that macro and micro estimates of price rigidity are the same cannot be rejected for most sectors at standard significance levels. These results are remarkable given the large methodological differences between the two approaches and suggest that highly disaggregated multi-sector models can describe well several aspects of the micro data.

Second, we study the extent to which sectoral price rigidity accounts for sectoral inflation and output responses to a monetary policy shock, as well as its implications for aggregate fluctuations.

\footnotetext{
${ }^{1}$ See Bils and Klenow (2004), Gagnon (2007), Klenow and Kryvtsov (2008), Eichenbaum, Jaimovich and Rebelo (2008), and Nakamura and Steinsson (2008a) for final goods; and Carlton (1986) for intermediate goods.

${ }^{2}$ See, for example, Gali and Gertler (1999), Kim (2000), Ireland (2001, 2003), Smets and Wouters (2003), Christiano, Eichenbaum and Evans (2005), and Bouakez, Cardia and Ruge-Murcia (2005).

${ }^{3}$ Our modelling approach builds on earlier multi-sector models in the real business cycle literature (see, for example, Long and Plosser, 1983 and 1987, Hornstein and Praschnick, 1997, and Horvath, 2000) and, most closely, on our own previous work (Bouakez, Cardia and Ruge-Murcia, 2008). The latter paper studies the role of input-output interactions for the transmission of monetary policy shocks and, for empirical purposes, focuses only on six broad sectors of the U.S. economy. Studying the implications of sectoral heterogeneity in a fully compelling manner, however, requires building a model with a finer level of disaggregation, a task that we indertake in this paper.
} 
The model generates substantial differences in the effects of monetary policy shocks across sectors, consistently with the findings of existing empirical studies (e.g., Barth and Ramey, 2001, Dedola and Lippi, 2003 and Peersman and Smets, 2005) that use Vector Autoregressions (VAR) and Ordinary Least Squares (OLS) regressions. Our results indicate that heterogeneity in price rigidity is the most important factor to understand the cross sectional heterogeneity in sectoral inflation responses, but that the most relevant characteristic to explain sectoral output responses is whether the sector produces a durable good.

Regarding the aggregate implications of sectoral price rigidity, we show that heterogeneity in the (implied) frequency of price changes amplifies the degree of aggregate money nonneutrality, multiplying the effects of a monetary policy shock on aggregate output by a factor of 6 . This amplification effect has also been discussed by Carvalho (2006) and Nakamura and Steinsson (2008b), who, however, calibrate price rigidity using micro data and abstract from capital accumulation. Carvalho abstracts from materials inputs as well, while Nakamura and Steinsson model materials inputs in a symmetric manner meaning that firms in a given sector use equal proportions of all goods. Our paper complements their work by showing that their result carries through in more general environments, while delivering independent estimates of sectoral price rigidity that can be compared with the micro estimates. We also show that heterogeneity in price rigidity has important implications for cost pass-through and for aggregate inflation. The degree to which changes in sectoral marginal costs are passed through to the consumer price index tends to be significantly lower in an economy with heterogenous price stickiness than in a symmetric economy characterized by the same average frequency of price changes. On the other hand, heterogeneity in sectoral inflation rates induces substantial persistence in the aggregate inflation rate. The latter result is important because standard sticky-price models generally predict a much lower aggregate inflation persistence than found in the data.

Finally, we examine the role of sectoral shocks in explaining sectoral dynamics. We find that sectoral productivity shocks account for the largest fraction of the variance of sectoral relative prices and marginal costs, whereas they explain only 5 percent of the variance of aggregate inflation. This result suggests that sectoral shocks are an important cause of the price changes observed at the micro level and that the observed volatility in sectoral inflation rates need not imply that money is neutral. A similar conclusion is reached by Boivin, Giannoni and Mihov (2007), and Mackowiak, Moench and Wiederholt (2008) using statistical factor models. The nature of the analysis undertaken by these authors, however, does not allow them to put an economic label on sector-specific shocks, although the former present suggestive evidence that these shocks are for the most part supply-side disturbances. An advantage of the structural estimation carried out in 
our paper is that it provides an economic interpretation for these shocks and enables one to study the mechanisms through which they affect the economy. For example, we show that idiosyncratic productivity shocks in one sector can have large effects on another via input-output interactions.

The paper is organized as follows: Section 2 develop a multi-sector Dynamic Stochastic General Equilibrium (DSGE) model with heterogenous production sectors, Section 3 discusses a number of econometric issues and our estimation strategy; Section 4 reports parameter estimates and examines the microeconomic implications of the model; Section 5 studies the effects of monetary policy shocks for sectoral output and inflation, and relative prices; Section 6 examines the implications of sectoral price rigidity for aggregate nonneutrality, cost pass-through and aggregate persistence and volatility, and computes the relative contribution of the aggregate and sectoral shocks to the variance of aggregate output and inflation; Section 7 documents the importance of sectoral shocks for the dynamics of sectoral variables; and, finally, Section 8 summarizes the main conclusions and results from our analysis.

\section{The Model}

\subsection{Production and Intermediate Consumption}

Production is carried out by continua of firms in each of $J$ sectors. Firms in the same sector are identical except for the fact that their goods are differentiated and, consequently, they have monopolistically competitive power. In contrast, firms in different sectors have different production functions, use different combinations of material and investment inputs, and face different nominal price frictions. Firm $l$ in sector $j$ produces output $y_{t}^{l j}$ using the technology

$$
y_{t}^{l j}=\left(z_{t}^{j} n_{t}^{l j}\right)^{\nu^{j}}\left(k_{t}^{l j}\right)^{\alpha^{j}}\left(H_{t}^{l j}\right)^{\gamma^{j}}
$$

where $z_{t}^{j}$ is a sector-specific productivity shock, $n_{t}^{l j}$ is labor, $k_{t}^{l j}$ is capital, $H_{t}^{l j}$ is materials inputs, and $\nu^{j}, \alpha^{j}, \gamma^{j}$ are strictly positive parameters that satisfy $\nu^{j}+\alpha^{j}+\gamma^{j}=1$. The sectoral productivity shock follows the process

$$
\ln \left(z_{t}^{j}\right)=\left(1-\rho_{z^{j}}\right) \ln \left(z_{s s}^{j}\right)+\rho_{z^{j}} \ln \left(z_{t-1}^{j}\right)+\epsilon_{z^{j}, t}
$$

where $\rho_{z^{j}} \in(-1,1), \ln \left(z_{s s}^{j}\right)$ is the unconditional mean, and the innovation $\epsilon_{z^{j}, t}$ is identically and independently distributed (i.i.d.) with zero mean and variance $\sigma_{z^{j}}^{2} \cdot{ }^{4}$

\footnotetext{
${ }^{4}$ Idiosyncratic productivity shocks are also assumed by Golosov and Lucas (2007), Gertler and Leahy (2008) and Midrigan (2008). In those models all shocks are drawn from the same distribution, while in our model the shock distribution depends on the sector to which the firm belongs.
} 
Materials inputs are a composite of goods produced by all firms in all sectors:

$$
H_{t}^{l j}=\prod_{i=1}^{J} \zeta_{i j}^{-\zeta_{i j}}\left(h_{i, t}^{l j}\right)^{\zeta_{i j}}
$$

where

$$
h_{i, t}^{l j}=\left(\int_{0}^{1}\left(h_{m i, t}^{l j}\right)^{(\theta-1) / \theta} d m\right)^{\theta /(\theta-1)},
$$

$h_{m i, t}^{l j}$ is the quantity of good produced by firm $m$ in sector $i$ that is purchased by firm $l$ in sector $j$ as materials input, $\zeta_{i j}$ is a nonnegative weight that satisfies the restriction $\sum_{i=1}^{J} \zeta_{i j}=1$, and $\theta>1$ is the elasticity of substitution between goods produced in the same sector. The Cobb-Douglas function in (2) is the special case of the CES (Constant Elasticity of Substitution) aggregator that is obtained when the elasticity parameter tends to one. This specification has the attractive property that the weight $\zeta_{i j}$ is equal to the share of sector $i$ in the materials input expenditures by sector $j$. These shares are computed in the empirical section of the paper using data from the Use Table of the U.S. Input-Output (I-O) accounts. Hence, by construction, the I-O Table of our model economy will be equal to that of the U.S. economy.

The capital stock is directly owned by firms and follows the law of motion

$$
k_{t+1}^{l j}=(1-\delta) k_{t}^{l j}+X_{t}^{l j}
$$

where $\delta \in(0,1)$ is the depreciation rate and $X_{t}^{l j}$ is an investment technology that combines different goods into units of capital. In particular,

$$
X_{t}^{l j}=\prod_{i=1}^{J} \kappa_{i j}^{-\kappa_{i j}}\left(x_{i, t}^{l j}\right)^{\kappa_{i j}}
$$

where

$$
x_{i, t}^{l j}=\left(\int_{0}^{1}\left(x_{m i, t}^{l j}\right)^{(\theta-1) / \theta} d m\right)^{\theta /(\theta-1)},
$$

$x_{m i, t}^{l j}$ is the quantity of good produced by firm $m$ in sector $i$ that is purchased by firm $l$ in sector $j$ for investment purposes, and $\kappa_{i j}$ is a nonnegative weight that satisfies $\sum_{i=1}^{J} \kappa_{i j}=1$. Exploiting the assumption of a Cobb-Douglas form in (5), this weight is estimated below as the share of sector $i$ in the investment input expenditures by sector $j$ from the Capital Flow Table of the I-O accounts. Since the $\kappa_{i j}$ s vary across sectors, the composition of the capital stock varies across sectors as well. 
The prices of the composites $H_{t}^{j}$ and $X_{t}^{j}$ are

$$
\begin{aligned}
Q_{t}^{H^{j}} & =\prod_{i=1}^{J}\left(p_{t}^{i}\right)^{\zeta_{i j}} \\
Q_{t}^{X^{j}} & =\prod_{i=1}^{J}\left(p_{t}^{i}\right)^{\kappa_{i j}}
\end{aligned}
$$

respectively, where

$$
p_{t}^{i}=\left(\int_{0}^{1}\left(p_{t}^{m i}\right)^{1-\theta} d m\right)^{1 /(1-\theta)},
$$

and $p_{t}^{m i}$ is the price of the good produced by firm $m$ in sector $i$.

Firms face convex costs when adjusting their capital stock and the nominal price of their good. Capital-adjustment costs are proportional to the current capital stock and take the quadratic form

$$
\Gamma_{t}^{l j}=\Gamma\left(X_{t}^{l j}, k_{t}^{l j}\right)=\frac{\chi}{2}\left(\frac{X_{t}^{l j}}{k_{t}^{l j}}-\delta\right)^{2} k_{t}^{l j},
$$

where $\chi$ is a nonnegative parameter. Similarly, the real per-unit cost of changing the nominal price is

$$
\Phi_{t}^{l j}=\Phi\left(p_{t}^{l j}, p_{t-1}^{l j}\right)=\frac{\phi^{j}}{2}\left(\frac{p_{t}^{l j}}{\pi_{s s} p_{t-1}^{l j}}-1\right)^{2},
$$

where $p_{t}^{l j}$ is the price of the good produced by firm $l$ in sector $j, \phi^{j} \geqslant 0$ is a sector-specific parameter, and $\pi_{s s}$ is the steady-state aggregate inflation rate. In the special case where $\phi^{j}=0$, the prices of goods produced in sector $j$ are flexible. ${ }^{5}$ In this model, there are neither temporary sales nor volume discounts. Also, since the price elasticity of demand does not depend on the use given to the good by the buyer, firms charge the same price to all consumers regardless of whether their output is used as investment good, consumption good, or materials input. ${ }^{6}$

The firm's problem is to maximize

$$
E_{\tau} \sum_{t=\tau}^{\infty} \beta^{t-\tau}\left(\frac{\Lambda_{\tau}}{\Lambda_{t}}\right)\left(\frac{d_{t}^{l j}}{P_{t}}\right),
$$

\footnotetext{
${ }^{5}$ The quadratic-cost model for nominal prices is due to Rotemberg (1982). This model has been used by, among others, Kim (2000) and Ireland $(2001,2003)$ to study the aggregate effects of monetary policy shocks. In their case study of price adjustment practices by a large U.S. manufacturer, Zbaracki et al. (2004) find that managerial and customer costs are 96 percent, while physical (or menu) costs are only 4 percent, of the total cost of changing prices. While physical costs are lump sum, and therefore nonconvex, managerial and customer costs are convex and increasing in the size of the adjustment.

${ }^{6}$ It is possible to extend the model to allow different prices for firms and households by assuming different elasticities of substitution in production (see eqs. (6) and (3)) and consumption (see eq. (16) below). However this extension requires additional assumptions that rule out arbitrage.
} 
where $d_{t}^{l j}$ are nominal profits, $P_{t}$ is the aggregate price index (to be defined below), $\beta \in(0,1)$ is a discount factor and $\Lambda_{t}$ is the consumers' marginal utility of wealth. Nominal profits are

$$
\begin{aligned}
d_{t}^{l j}= & p_{t}^{l j}\left(c_{t}^{l j}+\sum_{i=1}^{J} \int_{0}^{1} x_{l j, t}^{m i} d m+\sum_{i=1}^{J} \int_{0}^{1} h_{l j, t}^{m i} d m\right)-w_{t}^{l j} n_{t}^{l j}-\sum_{i=1}^{J} \int_{0}^{1} p_{t}^{m i} x_{m i, t}^{l j} d m-\sum_{i=1}^{J} \int_{0}^{1} p_{t}^{m i} h_{m i, t}^{l j} d m \\
& -\Gamma_{t}^{l j} Q_{t}^{X^{j}}-\Phi_{t}^{l j} p_{t}^{l j}\left(c_{t}^{l j}+\sum_{i=1}^{J} \int_{0}^{1} x_{l j, t}^{m i} d m+\sum_{i=1}^{J} \int_{0}^{1} h_{l j, t}^{m i} d m\right),
\end{aligned}
$$

where $c_{t}^{l j}$ is final consumption, $w_{t}^{l j}$ is the nominal wage, and $x_{l j, t}^{m i}$ and $h_{l j, t}^{m i}$ are respectively the quantities sold to firm $m$ in sector $i$ as materials input and investment good. The maximization involves selecting optimal sequences $\left\{n_{t}^{l j}, x_{m i, t}^{l j}, h_{m i, t}^{l j}, k_{t+1}^{l j}, p_{t}^{l j}\right\}_{t=\tau}^{\infty}$ subject to the production function (1), the law of motion for capital (4), total demand for good $l j$, the condition that supply must meet demand at the posted price, and the initial capital stock and price. The solution of the firm's problem delivers the following demand functions for materials and investment inputs:

$$
\begin{aligned}
& x_{m i, t}^{l j}=\kappa_{i j}\left(p_{t}^{m i} / p_{t}^{i}\right)^{-\theta}\left(p_{t}^{i} / Q_{t}^{X^{j}}\right)^{-1} X_{t}^{l j} \\
& h_{m i, t}^{l j}=\zeta_{i j}\left(p_{t}^{m i} / p_{t}^{i}\right)^{-\theta}\left(p_{t}^{i} / Q_{t}^{H^{j}}\right)^{-1} H_{t}^{l j} .
\end{aligned}
$$

For these demand functions, the relations $\sum_{i=1}^{J} \int_{0}^{1} p_{t}^{m i} x_{m i, t}^{l j} d m=\sum_{i=1}^{J} p_{t}^{i} x_{i, t}^{l j}=Q_{t}^{X^{j}} X_{t}^{l j}$ and $\sum_{i=1}^{J} \int_{0}^{1} p_{t}^{m i} h_{m i, t}^{l j} d m=$ $\sum_{i=1}^{J} p_{t}^{i} h_{i, t}^{l j}=Q_{t}^{H^{j}} H_{t}^{l j}$ hold.

\subsection{Final Consumption}

Consumers are identical, infinitely lived, and their number is constant and normalized to one. The representative consumer maximizes

$$
E_{\tau} \sum_{t=\tau}^{\infty} \beta^{t-\tau} U\left(C_{t}, M_{t} / P_{t}, 1-N_{t}\right),
$$

where $U(\cdot)$ is an instantaneous utility function that satisfies the Inada conditions and is assumed to be strictly increasing in all arguments, strictly concave and twice continuously differentiable, $C_{t}$ is consumption, $M_{t}$ is the nominal money stock, $N_{t}$ is hours worked, and the time endowment has been normalized to 1 .

Consumption is an aggregate of all available goods:

$$
C_{t}=\prod_{j=1}^{J}\left(\xi^{j}\right)^{-\xi^{j}}\left(c_{t}^{j}\right)^{\xi^{j}}
$$


where $\xi^{j}$ is a nonnegative weight that satisfies $\sum_{j=1}^{J} \xi^{j}=1$ and

$$
c_{t}^{j}=\left(\int_{0}^{1}\left(c_{t}^{l j}\right)^{(\theta-1) / \theta} d l\right)^{\theta /(\theta-1)}
$$

with $c_{t}^{l j}$ the final consumption of the good produced by firm $l$ in sector $j$. As before, the CobbDouglas function in (15) implies that the weight $\xi^{j}$ is equal to the expenditure share of sector $j$, which can be directly computed using data from the National Income and Product Accounts (NIPA). One implication of equations (15) and (16) is that goods produced in the same sector (for example, barley and wheat) are better consumption substitutes than goods produced in different sectors (for example, barley and insurance brokerage).

Hours worked are an aggregate of the hours supplied to each firm in each sector:

$$
N_{t}=\left(\sum_{j=1}^{J}\left(n_{t}^{j}\right)^{(\varsigma+1) / \varsigma}\right)^{\varsigma /(\varsigma+1)}
$$

where $\varsigma>0$ is a constant parameter and

$$
n_{t}^{j}=\int_{0}^{1} n_{t}^{l j} d l
$$

is the number of hours worked in sector $j$, with $n_{t}^{l j}$ being the number of hours worked in firm $l$ in sector $j$. This specification is attractive for several reasons. First, it is a simple manner to introduce limited labor mobility across sectors and, consequently, heterogeneity in wages and hours while preserving the representative-agent setup. Second, it includes perfect labor mobility between sectors as a special case of (17) when $\varsigma$ tends to infinity. Finally, it implies that labor is perfectly mobile within sectors. As a result, wages and hours in firms of the same sector will be the same. This allows us to focus on an equilibrium that is symmetric within sectors but still asymmetric across sectors. The implication that the cross-sectional dispersion of wages and hours is larger between, than within, sectors is in line with empirical evidence reported by Davis and Haltiwanger (1991).

Since Ngai and Pissarides (2007) show that logarithmic preferences are one of the conditions for the existence of an aggregate balanced growth path in a multi-sector economy, we specialize the instantaneous utility function to

$$
U\left(C_{t}, M_{t} / P_{t}, 1-N_{t}\right)=\log \left(C_{t}\right)+v_{t} \log \left(M_{t} / P_{t}\right)+\eta_{t} \log \left(1-N_{t}\right),
$$


where $v_{t}$ and $\eta_{t}$ are preference shocks. These shocks disturb the intratemporal first-order conditions that determine money demand and labor supply, respectively, and follow the processes

$$
\begin{aligned}
& \ln \left(v_{t}\right)=\left(1-\rho_{v}\right) \ln \left(v_{s s}\right)+\rho_{\eta} \ln \left(v_{t-1}\right)+\epsilon_{v, t}, \\
& \ln \left(\eta_{t}\right)=\left(1-\rho_{\eta}\right) \ln \left(\eta_{s s}\right)+\rho_{\eta} \ln \left(\eta_{t-1}\right)+\epsilon_{\eta, t},
\end{aligned}
$$

where $\rho_{v}, \rho_{\eta} \in(-1,1), \ln \left(v_{s s}\right)$ and $\ln \left(\eta_{s s}\right)$ are unconditional means, and the innovations $\epsilon_{v, t}$ and $\epsilon_{\eta, t}$ are $i . i . d$. with zero mean and variances $\sigma_{v}^{2}$ and $\sigma_{\eta}^{2}$, respectively.

The aggregate price index is defined as

$$
P_{t}=\prod_{j=1}^{J}\left(p_{t}^{j}\right)^{\xi^{j}}
$$

where

$$
p_{t}^{j}=\left(\int_{0}^{1}\left(p_{t}^{l j}\right)^{1-\theta} d l\right)^{1 /(1-\theta)} .
$$

Since $P_{t}$ is the price index associated with the bundle of goods purchased by consumers, it will be the equivalent of the Consumer Price Index (CPI) in our model.

Financial assets are money, a one-period interest-bearing nominal bond, and shares in a mutual fund for each of the $J$ productive sectors. The consumer enters period $t$ with $M_{t-1}$ units of currency, $B_{t-1}$ nominal private bonds, and $s_{t-1}^{j}$ shares in mutual fund $j=1, \ldots, J$, and then receives interests, dividends, wages and a lump-sum transfer from the government. These resources finance consumption and the purchase of assets to be carried over to the following period. The consumer's dynamic budget constraint (in real terms) is

$$
\begin{aligned}
\sum_{j=1}^{J} \int_{0}^{1}\left(\frac{p_{t}^{l j} c_{t}^{l j}}{P_{t}}\right) d l+b_{t}+m_{t}+\sum_{j=1}^{J} \int_{0}^{1}\left(\frac{a_{t}^{l j} s_{t}^{l j}}{P_{t}}\right) d l= & \sum_{j=1}^{J} \int_{0}^{1}\left(\frac{w_{t}^{l j} n_{t}^{l j}}{P_{t}}\right) d l+\frac{R_{t-1} b_{t-1}}{\pi_{t}}+\frac{m_{t-1}}{\pi_{t}} \\
& +\sum_{j=1}^{J} \int_{0}^{1}\left(\frac{\left(d_{t}^{l j}+a_{t}^{l j}\right) s_{t-1}^{l j}}{P_{t}}\right) d l+\frac{\Upsilon_{t}}{P_{t}},
\end{aligned}
$$

where $b_{t}=B_{t} / P_{t}$ is the real value of nominal bond holdings, $m_{t}=M_{t} / P_{t}$ is real money balances, $R_{t}$ is the gross nominal interest rate on bonds that mature at time $t+1, \pi_{t}$ is the gross inflation rate between periods $t-1$ and $t, \Upsilon_{t}$ is a government lump-sum transfer, and $a_{t}^{j}$ and $d_{t}^{j}$ are, respectively, the price of a share in, and the dividend paid by, mutual fund $j$.

The consumer's utility maximization is carried out by choosing optimal sequences $\left\{c_{t}^{l j}, n_{t}^{l j}, M_{t}\right.$, $\left.B_{t}, s_{t}^{j}\right\}_{t=\tau}^{\infty}$ subject to the sequence of dynamic budget constraints, a no-Ponzi-game condition, and 
initial asset holdings. The first-order conditions for this problem determine the labor supplied to each firm, the demand for money and other assets, and the consumption demand for each good. In particular, the demand for the good produced by firm $l$ in sector $j$ is

$$
c_{t}^{l j}=\xi^{j}\left(\frac{p_{t}^{l j}}{p_{t}^{j}}\right)^{-\theta}\left(\frac{p_{t}^{j}}{P_{t}}\right)^{-1} C_{t} .
$$

Using this demand function and the definition of the price indices, it is easy to show that $\sum_{j=1}^{J} \int_{0}^{1} p_{t}^{l j} c_{t}^{l j} d l=$ $\sum_{j=1}^{J} p_{t}^{j} c_{t}^{j}=P_{t} C_{t}$

\subsection{Fiscal and Monetary Policy}

The government combines both fiscal and monetary authorities. Fiscal policy consists of lump-sum transfers to consumers each period, which are financed by printing additional money. Thus, the government budget constraint is

$$
\Upsilon_{t} / P_{t}=m_{t}-m_{t-1} / \pi_{t}
$$

where the term in the right-hand side is seigniorage revenue at time $t$. Money is supplied by the government according to $M_{t}=\mu_{t} M_{t-1}$, where $\mu_{t}$ is the stochastic gross rate of money growth, which follows the process

$$
\ln \left(\mu_{t}\right)=\left(1-\rho_{\mu}\right) \ln \left(\mu_{s s}\right)+\rho_{\mu} \ln \left(\mu_{t-1}\right)+\epsilon_{\mu, t},
$$

where $\rho_{\mu} \in(-1,1), \ln \left(\mu_{s s}\right)$ is the unconditional mean, and the innovation $\epsilon_{\mu, t}$ is $i . i . d$. with zero mean and variance $\sigma_{\mu}^{2}$.

\subsection{Aggregation}

In equilibrium, net private bond holdings equal zero because consumers are identical, the total share holdings in sector $j$ add up to one, and firms in the same sector are identical, so that $p_{t}^{j}=p_{t}^{l j}$, $c_{t}^{j}=c_{t}^{l j}, n_{t}^{j}=n_{t}^{l j}$ and $d_{t}^{j}=d_{t}^{l j}$. Then, the aggregate equivalent of the consumer's budget constraint is

$$
\sum_{j=1}^{J} \frac{p_{t}^{j} c_{t}^{j}}{P_{t}}+m_{t}=\sum_{j=1}^{J} \frac{w_{t}^{j} n_{t}^{j}}{P_{t}}+\sum_{j=1}^{J} \frac{d_{t}^{j}}{P_{t}}+\frac{m_{t-1}}{\pi_{t}}+\frac{\Upsilon_{t}}{P_{t}} .
$$

Substituting in the government budget constraint (23) and multiplying through by the price level yield

$$
\sum_{j=1}^{J} p_{t}^{j} c_{t}^{j}=\sum_{j=1}^{J} w_{t}^{j} n_{t}^{j}+\sum_{j=1}^{J} d_{t}^{j}
$$


Define the value of gross output produced by sector $j$

$$
V_{t}^{j} \equiv p_{t}^{j}\left(c_{t}^{j}+\sum_{i=1}^{J} x_{j, t}^{i}+\sum_{i=1}^{J} h_{j, t}^{i}\right)
$$

and the sum of all adjustment costs in sector $j$

$$
A_{t}^{j}=\Gamma_{t}^{j} Q_{t}^{X^{j}}+\Phi_{t}^{j} p_{t}^{j}\left(c_{t}^{j}+\sum_{i=1}^{J} x_{j, t}^{i}+\sum_{i=1}^{J} h_{j, t}^{i}\right) .
$$

Then, aggregate nominal dividends are

$$
\sum_{j=1}^{J} d_{t}^{j}=\sum_{j=1}^{J} V_{t}^{j}-\sum_{j=1}^{J} w_{t}^{j} n_{t}^{j}-\sum_{j=1}^{J} Q_{t}^{X^{j}} X_{t}^{j}-\sum_{j=1}^{J} Q_{t}^{H^{j}} H_{t}^{j}-\sum_{j=1}^{J} A_{t}^{j},
$$

where we have used $\sum_{i=1}^{J} p_{t}^{i} x_{i, t}^{j}=Q_{t}^{X^{j}} X_{t}^{j}$ and $\sum_{i=1}^{J} p_{t}^{i} h_{i, t}^{j}=Q_{t}^{H^{j}} H_{t}^{j}$. The nominal value added in sector $j$ is denoted by $Y_{t}^{j}$ and is defined as the value of gross output produced by that sector minus the cost of materials inputs

$$
Y_{t}^{j}=V_{t}^{j}-Q_{t}^{H^{j}} H_{t}^{j}
$$

Substituting (28) and (29) into (25), using $\sum_{j=1}^{J} p_{t}^{j} c_{t}^{j}=P_{t} C_{t}$, and rearranging yield

$$
\sum_{j=1}^{J} Y_{t}^{j}=P_{t} C_{t}+\sum_{j=1}^{J} Q_{t}^{X^{j}} X_{t}^{j}+\sum_{j=1}^{J} A_{t}^{j}
$$

That is, aggregate output equals private consumption plus investment and the sum of all adjustment costs in all sectors. Notice that aggregate output in our model is measured as the sum of sectoral values added, just as in the U.S. National Income and Product Accounts.

The equilibrium of the model is symmetric within sectors but asymmetric between sectors. Thus, relative sectoral prices are not all equal to one and real wages and allocations are different across sectors. The model is solved numerically by log-linearizing the first-order and equilibrium conditions around the deterministic steady state to obtain a system of linear difference equations with expectations. The rational-expectation solution of this system is found using the method proposed in Blanchard and Kahn (1980).

\section{Estimation Issues}

\subsection{Disaggregation Level}

The empirical analysis of the model is based on a highly disaggregated partition of the U.S. economy. We consider thirty sectors that roughly correspond to the two-digit Standard Industrial 
Classification (SIC) and are listed in Table 1, along with the Major Group categories that they include. Agriculture includes the production of crops and livestock, agriculture-related services, and forestry. Construction includes building and heavy construction and special trade contractors. The four mining sectors are Major Groups 10 and 12 to 14 . The twenty manufacturing sectors are Major Groups 20 to 39. Transport and utilities includes all forms of passenger and freight transportation, communications, and electric, gas and sanitary services. Trade includes both wholesale and retail trade. FIRE is finance, insurance and real estate. Finally, other services includes personal, business, recreation, repair, health, legal, educational and social services as well as lodging. At this level of disaggregation, agriculture, mining and construction all include some service industries. For example, oil and gas extraction includes drilling and exploration services.

The level of disaggregation is driven by two considerations, namely data availability and computational costs. The Bureau of Labor Statistics (BLS) produces sectoral data at discrete levels of disaggregation (divisions, major groups, industry groups and industries). Using a higher disaggregation level (say, industry groups) would involve a nontrivial increase in computational complexity because finding the steady state allocations and prices requires solving a system of $3 J+1$ nonlinear equations, where $J$ is the number of sectors. Also, Dale Jorgenson's data on sectoral input expenditures, which we use to estimate the parameters of the sectoral production functions, are only available for major groups of the SIC. As we will see below, the level of disaggregation used here allows us to paint a fairly rich portrait of both the macro and microeconomic effects of monetary policy.

\subsection{Estimation Strategy}

The estimation of this model is computationally demanding for two reasons. First, the number of structural parameters is very large and, second, the steady state and solution of the model need to be calculated in every iteration of the optimization algorithm. As noted above, finding the steady state requires solving a large system of nonlinear equations. We respond to this challenge by exploiting the properties of the model and various data to estimate or calibrate the parameters that determine the steady state. Then, with those parameter values fixed, we estimate the parameters that drive the model dynamics using the Simulated Method of Moments (SMM).

The discount rate $(\beta)$ is set to 0.997 , which is the sample average of the inverse of the gross $e x$ post real interest rate for the period 1959Q2 to 2002Q4. The depreciation rate is set to $\delta=0.02 .^{7}$ The elasticity of substitution between goods produced in the same sector $(\theta)$ is set to 8 . This value

\footnotetext{
${ }^{7}$ In preliminary work, we considered using the sector-specific depreciation rates computed by Jorgenson and Fraumeni (1987) and which very between 0.01 and 0.04 . However, results are basically the same as those reported here.
} 
is in the middle of the range used in the literature, and implies an average markup over marginal cost of approximately 15 percent. ${ }^{8}$ The parameter that determines the elasticity of substitution between hours worked in different sectors is set to 1, following the empirical work by Horvath (2000). ${ }^{9}$ The consumption weights $\left(\xi^{j}\right)$ are the average expenditure shares in NIPA from 1959 to 1995 and were taken from Horvath (2000, p. 87). These weights are listed in the second column of Table $1 .{ }^{10}$ The input weights $\zeta_{i j}$ and $\kappa_{i j}$ are equal to the share of sector $i$ in the materials and investment input expenditures by sector $j$, respectively. These shares are computed using data from the 1992 U.S. Input-Output (I-O) accounts. ${ }^{11}$ More precisely, the $\zeta_{i j}$ s are computed using the Use Table, which contains the value of each input used by each U.S. industry, while the $\kappa_{i j}$ s are computed using the Capital Flow Table, which reports the purchases of new structures, equipment and software allocated by using industry. ${ }^{12}$ By construction, $\zeta_{i j}, \kappa_{i j} \in[0,1]$ and $\sum_{i=1}^{J} \zeta_{i j}=\sum_{i=1}^{J} \kappa_{i j}=1$ for all $j$.

\subsection{Estimation of Production Function Parameters}

The production function parameters were estimated using the yearly data on nominal expenditures on capital, labor and materials inputs by each sector collected by Dale Jorgenson for the period 1958 to $1996 .^{13}$ The nominal expenditures predicted by the model may be obtained from the

\footnotetext{
${ }^{8}$ For example, Ireland (2001) sets $\theta$ to 6 while Barsky, House and Kimball (2007) set it to 11. Sensitivity analysis indicates that our results are robust to using other values employed in the literature.

${ }^{9}$ Horvath estimates $\varsigma$ from an Ordinary Least Square regression of the change in the relative labor supply on the change in the relative labor share using sectoral U.S. data and finds $\varsigma=0.9996$ with a standard error of 0.0027 .

${ }^{10}$ Our sector definitions differ from Horvath's in that we respectively combine into one sector: agricultural products and agricultural services; motor vehicles and transportation equipment; and transportation services, communications, electric and gas utilities, and water and sanitary services. The weights in Table 1 have been aggregated accordingly.

${ }^{11} \mathrm{I}-\mathrm{O}$ tables do evolve over time, for example as a result of technological innovation, but the change is relatively moderate at the level of disaggregation used here. We carried out a small number of sensitivity experiments and found our results to be robust to small perturbations around the values used.

${ }^{12}$ We equate commodities with sectors as in the theoretical model where goods of type $j$ are produced only by sector $j$. This assumption means that we implicitly treat the Make Table of the I-O accounts as diagonal and allows us to estimate the weights using the Use Table alone. The Make Table reports the value of each commodity produced by each domestic industry and, in practice, is not perfectly diagonal. The reason is that the I-O accounts assign a small number of commodities to a Major Group different from the one where they are produced. For example, printed advertisement is treated as a business service (SIC 73) despite the fact that it is actually produced by printing and publishing (SIC 27). In order to quantify the importance of the off-diagonal elements of the Make Table, we computed the share of each commodity type that is produced in each sector. Since the diagonal elements vary between 0.89 and 1 , we conclude that the original assumption that associates each commodity type with only one sector is a reasonable approximation for the U.S. economy at this level of disaggregation.

${ }^{13}$ Jorgenson records separately expenditures on materials and energy inputs. In order to be consistent with the model, where energy is indistinguishable from other materials inputs, we add these two series into a single expenditure category. The complete data set is available at http://post.economics.harvard.edu/faculty/jorgenson/data and is described in Jorgenson and Stiroh (2000).
} 
first-order conditions of the firm's problem

$$
\begin{aligned}
\nu^{j}\left(\psi_{t}^{j} P_{t} y_{t}^{j}\right) & =w_{t}^{j} n_{t}^{j}, \\
\gamma^{j}\left(\psi_{t}^{j} P_{t} y_{t}^{j}\right) & =\sum_{i=1}^{J} p_{t}^{i} h_{i, t}^{j}, \\
\alpha^{j}\left(\psi_{t}^{j} P_{t} y_{t}^{j}\right) & =\left(\left(\frac{\Lambda_{t-1}}{\beta \Lambda_{t}}\right) \Omega_{t-1}^{j}-(1-\delta) \Omega_{t}^{j}\right) P_{t} k_{t}^{j}+Q_{t}^{X^{j}} k_{t}^{j}\left(\frac{\partial \Gamma_{t}}{\partial k_{t}^{j}}\right),
\end{aligned}
$$

where $\psi_{t}^{j}$ and $\Omega_{t}^{j}$ are, respectively, the real marginal cost and the real shadow price of capital in sector $j$. Since, in equilibrium, firms in the same sector are identical, the firm superscripts are dropped. The right-hand sides of these equations are, respectively, the wage bill, total expenditures on materials inputs, and the opportunity cost (net of capital gains) of the capital stock plus net adjustment costs. Jorgenson's data are empirical counterparts of these expressions, but the mapping for capital is imperfect because the data do not include adjustment costs and take into account distortionary taxes, from which our model abstracts (see Jorgenson and Stiroh, 2000, Appendix B). Although the data set does not contain observations on $\psi_{t}^{j} P_{t} y_{t}^{j}$, it is possible to construct estimates of $\alpha^{j}, \nu^{j}$, and $\gamma^{j}$ as follows. Use two of the three ratios: $(31) /(32),(31) /(33)$ and $(32) /(33)$, and the condition $\nu^{j}+\alpha^{j}+\gamma^{j}=1$ to obtain a system of three equations with three unknowns. ${ }^{14}$ The unique solution of this system delivers an observation of the production function parameters for a given year. Our estimates of $\nu^{j}, \alpha^{j}$ and $\gamma^{j}$ are the sample averages of these yearly observations and their standard deviations are $\sqrt{\sigma^{2} / T}$ where $\sigma^{2}$ is the variance of the yearly observations and $T=39$ is the sample size. ${ }^{15}$

Estimates of the production function parameters are reported in Table 2. These estimates indicate substantial heterogeneity in capital, labor and materials intensities across sectors. Services sectors, especially trade, tend to be labor intensive but so are also construction, coal mining and some manufacturing sectors like instruments, and printing and publishing. Mining sectors are generally the most capital intensive of the economy, while construction is the least capital intensive. Material intensity tends to be relatively low in services and mining compared with manufacturing, construction and agriculture. Some manufacturing sectors like oil refining, food products, textile mill products, and lumber and wood are extremely intensive in materials. This heterogeneity in

\footnotetext{
${ }^{14}$ Given any two ratios, the third one is redundant and may be trivially derived from the other two. Hence, estimates of the production function parameters are independent of the particular pair of ratios employed.

${ }^{15}$ In deriving equation (33) from the first-order condition for $k_{t+1}^{j}$, we used the assumption of rational expectations. Hence, this equation holds up to a mean-zero forecast error. This adds extra noise to the yearly estimates of all production function parameters. However, since the variance of this forecasts error is likely to be small compared with that of the other terms, and since we average over yearly estimates, it is reasonable to assume that the effect of this error on point estimates is small.
} 
production function parameters is statistically significant in that tests of the null hypothesis that $\nu^{j}, \gamma^{j}$ and $\alpha^{j}$ are equal in all sectors are strongly rejected by the data.

\subsection{Simulated Method of Moments}

The remaining parameters are estimated by the Simulated Method of Moments (SMM) using sectoral and aggregate U.S. time series at the quarterly frequency for the period 1964Q1 to 2002Q4. The use of Simulated Method of Moments (SMM) for the estimation of DSGE models was proposed by Lee and Ingram (1991) and Duffie and Singleton (1993). Previous applications include Klein and Jonsson (1996), Coenen and Levin (2004) and Coenen and Wieland (2005) for linear models, and Kim and Ruge-Murcia (2007) for nonlinear models. Ruge-Murcia (2007) uses Monte-Carlo analysis to compare various methods used in the estimation of DSGE models and finds that moment-based estimators are less affected by the stochastic singularity of DSGE models and are generally more robust to misspecification than Maximum Likelihood. ${ }^{16}$ The sample starts in 1964 because data on wages in the service sector are available only after this date, and ends in 2002 because thereafter the BLS stopped reporting sectoral data under the SIC codes.

The sectoral data consist of quarterly series of real wages and PPI (Producer Price Index) inflation rates, computed using raw data taken from the BLS web site (www.bls.gov). Unfortunately, these data are not available for all thirty sectors in our model. We use sectoral wages for construction, all manufacturing sectors (except electric machinery and instruments for which the data are not available for the complete sample period) and all services sectors. Sectoral wages are constructed by dividing the monthly observations of average weekly earning of production workers by the CPI and averaging over the three months of each quarter.

We use sectoral inflation for the fourteen sectors listed in Table 3 for which it is possible to match commodity-based PPIs with their respective sector. Matching commodity-based PPIs with sectors allows us to address the fact that the BLS only started to construct industry-level PPIs in the mid-1980s. We assess the quality of the match by computing the correlation between the inflation rates constructed using commodity-based and industry-level PPIs for the periods where both index types are available. These correlations are reported in Table 3 and vary between 0.59 for oil and natural gas to almost 1 for tobacco products. ${ }^{17}$ Notice that although the data set on

\footnotetext{
${ }^{16}$ In this application, the length of the simulated series relative to the sample size is 20 and the weighting matrix is the inverse of the matrix with the long-run variance of the moments along the main diagonal and zeros in the offdiagonal elements. The latter is computed using the Newey-West estimator with a Barlett kernel and Newey-West fixed bandwidth, that is, the integer of $4(T / 100)^{2 / 9}$ where $T$ is the sample size, but results are reasonably robust to using other bandwidths. For the model simulation, innovations are drawn from normal distributions.

${ }^{17}$ We were unable to compute this correlation for agriculture because no industry-level PPI is available. In preliminary work, we considered using the commodity-based PPI for metals but the correlation with its industrylevel equivalent was only 0.148 .
} 
sectoral prices and wages is incomplete, sector specific parameters will be identified by our structural estimation approach because these parameters also affect observable aggregate and other sectoral variables through general equilibrium effects. Since the raw data are seasonally unadjusted, we control for seasonal effects by regressing each series on seasonal dummies and purging the seasonal components.

The aggregate data consist of the quarterly series of the rate of inflation, the rate of nominal money growth, the nominal interest rate, per-capita real money balances, per-capita investment and per-capita consumption. With the exceptions noted below, the raw data were taken from the Federal Reserve Economic Database (FRED) available from the Federal Reserve Bank of St-Louis web site (www.stls.frb.org). The inflation rate is the percentage change in the CPI. The rate of nominal money growth is the percentage change in M2. The nominal interest rate is the threemonth treasury bill rate. Real money balances are computed as the ratio of M2 per capita to the CPI. Real investment and consumption are measured, respectively, by gross private domestic investment and personal consumption expenditures per capita divided by the CPI. The raw investment and consumption series were taken from NIPA. These data are available from the BEA web site (www.bea.gov). Real balances, investment and consumption are computed in per-capita terms in order to make the data compatible with the model, where there is no population growth. The population series corresponds to the quarterly average of the mid-month U.S. population estimated by the BEA. Except for the nominal interest rate, all data are seasonally adjusted at the source. Since the variables in the model are expressed in percentage deviations from the steady state, all series were logged and quadratically detrended.

In summary, the moments used to estimate the model are the variances and first-order autocovariances of the following 43 series: per-capita consumption, investment and real money balances; the rates of money growth, nominal interest, and CPI inflation; the rates of PPI inflation in agriculture, coal mining, oil and gas extraction, nonmetallic mining, food products, tobacco products, lumber and wood, furniture and fixtures, paper, chemicals, oil refining, rubber and plastics, leather, and stone, clay and glass; and the real wages in construction, all twenty manufacturing sectors (except for electric machinery and for instruments) and all four service sectors. These 86 moments are used to identify 47 structural parameters. The parameters are 30 sectoral price rigidities, the capital adjustment cost parameter, and the autocorrelation and standard deviation of the productivity, money demand, labor supply and monetary policy shocks. Estimating both parameters of the productivity-shock processes for all sectors would mean estimating 60 parameters. Hence, in order to economize degrees of freedom and sharpen identification, we limit shock heterogeneity to the Division level of the SIC. Thus, we assume one distribution each for agriculture (Division A), 
all mining sectors (Division B), construction (Division C), all manufacturing sectors (Division D), and all services sectors (Divisions E through I). This means that we estimate the parameters of five rather than of thirty shock distributions. Since draws are independent, however, shock realizations will be different in different sectors, whether they are in the same Division or not.

\section{Parameter Estimates and Micro Implications}

In this section, we report SMM estimates of the structural parameters of the multi-sector model and examine the microeconomic implications of the model. In particular, we compare our estimates of sectoral price rigidity and the realized price adjustment costs with those based on micro data. We also report SMM estimates for a version of the model where price rigidity is the same in all sectors.

\subsection{Sectoral Price Rigidity}

SMM estimates of the price rigidity parameters are reported in Table 4. The magnitude of this parameter varies greatly across sectors and the null hypothesis that its true value is the same for all sectors is strongly rejected by the data ( $p$-value $<0.0001)$. Hence, heterogeneity in price rigidity is quantitatively important and statistically significant.

The null hypothesis that prices are flexible (that is, $\phi=0$ ) cannot be rejected at the 5 percent level for 17 out of 30 sectors in our sample. Thus, at this level of disaggregation, the majority of sectors in the U.S. economy are flexible price sectors. This point is illustrated in a simple but revealing way in Figure 1, which plots the distribution of price rigidity parameters. ${ }^{18}$ This distribution is highly positively skewed and has a median of only 4.80. Flexible price sectors include producers of primary goods (agriculture and mining), manufactured commodities (for example, tobacco, chemical and petroleum products) and some durable goods (for example, electric and nonelectric machinery, and instruments).

The null of price flexibility can be rejected for 13 sectors and the magnitude of $\phi$ is especially large in eight sectors, namely trade, transport and utilities, primary metal, construction, food, apparel, furniture, and leather goods. Importantly, the first two sectors (trade, and transport and utilities) are services, and account respectively for 25 and 21 percent of the Consumer Price Index in the model economy. These results suggest that price rigidity in the U.S. economy is mostly concentrated in services.

\footnotetext{
${ }^{18}$ In related work, Carvalho and Dam (2008) construct a cross-sectional distribution of price stickiness using aggregate U.S. data alone. Their approach is complementary to ours and is based on the observation that different sectors may be relatively more important than others in determining the response of aggregate variables to shocks at different frequencies.
} 
In what follows, we quantitatively compare our macro estimates of sectoral price rigidity with estimates computed by Bils and Klenow (2004) and Nakamura and Steinsson (2008a) using U.S. micro data. One difficulty, however, is that micro-based estimates of price rigidity are usually reported in terms of frequency of adjustments (from which durations may be computed) but our quadratic cost model expresses price rigidity in terms of the size of, rather than the time interval between, price adjustments. In order to derive the duration spells implied by our rigidity estimates, we exploit the observational equivalence between the Phillips curves in the (log-linearized) quadratic-cost and Calvo models. To see this equivalence, note that the sectoral Phillips curve for a generic sector $j$ in our model is

$$
E_{t} \hat{\pi}_{t+1}^{j}=\frac{1}{\beta} \hat{\pi}_{t}^{j}-\frac{\theta-1}{\beta \phi^{j}}\left(\hat{\psi}_{t}^{j}-\hat{\mathrm{p}}_{t}^{j}\right)
$$

where $\mathrm{p}_{t}^{j}=p_{t}^{j} / P_{t}$ is the real price and the circumflex denotes deviation from steady state. On the other hand, the sectoral Phillips curve that would be obtained in a version of the model where firms follow Calvo pricing is

$$
E_{t} \hat{\pi}_{t+1}^{j}=\frac{1}{\beta} \hat{\pi}_{t}^{j}-\frac{\left(1-\varrho^{j}\right)\left(1-\beta \varrho^{j}\right)}{\beta \varrho^{j}}\left(\hat{\psi}_{t}^{j}-\hat{\mathrm{p}}_{t}^{j}\right)
$$

where $\varrho^{j}$ is the probability of not changing prices. The two curves are isomorphic and, given numerical values of the elasticity of substitution $(\theta)$ and the discount rate $(\beta)$, imply a correspondence between the rigidity parameter $\phi^{j}$ in the quadratic cost function and the Calvo probability, $\varrho^{j}$. In particular, given a value of $\phi^{j}>0$, the sectoral Calvo probability is the smaller root that solves ${ }^{19}$

$$
\frac{\theta-1}{\phi^{j}}=\frac{\left(1-\varrho^{j}\right)\left(1-\varrho^{j} \beta\right)}{\varrho^{j}}
$$

Since under Calvo pricing, signals are independent across firms and time, the expected price duration is $1 /\left(1-\varrho^{j}\right)$. Notice that, by construction, the expected duration cannot be shorter than one period, which is a quarter in our model. The Calvo probabilities and durations implied by our estimates of $\phi^{j}$ are reported in Table 4. Since these variables are monotonic transformations of the $\phi^{j} \mathrm{~s}$, their distributions share the positive skewness observed in Figure 1.

Durations constructed from the micro-based estimates are also reported in Table 4. The mean durations for producer prices were computed as the inverse of the monthly frequencies of price

\footnotetext{
${ }^{19}$ This is a quadratic equation with roots

$$
\frac{(\theta-1)+\phi^{j}(1+\beta) \pm \sqrt{\left((1-\theta)-\phi^{j}(1+\beta)\right)^{2}-4 \beta\left(\phi^{j}\right)^{2}}}{2 \beta \phi^{j}} .
$$
}

Since $\left((1-\theta)-\phi^{j}(1+\beta)\right)^{2}-4 \beta\left(\phi^{j}\right)^{2}>0$ and $(\theta-1)+\phi^{j}(1+\beta)>0$, it follows that both roots are real and positive. One can further show that one root is larger than 1 and the other one is less than 1. 
changes for Major Industries reported by Nakamura and Steinsson (see their Table 7), divided by 3 to express them in quarters. ${ }^{20}$ The mean durations of consumer prices were estimated as follows. First, each Entry Level Item (ELI) category in the micro data was manually matched into one of our sector definitions. Then, sectoral price durations were computed as the weighted average of the durations of ELIs in that sector. The raw ELI durations are those reported by Bils and Klenow (2004) and Nakamura and Steinsson (2008a), and the weights are proportional to those given to each ELI in the CPI. ${ }^{21}$ In total, we constructed four sets of micro estimates respectively based on PPI prices, regular CPI prices and final CPI prices from Nakamura and Steinsson, and final CPI prices from Bils and Klenow. Final CPI prices include the effect of sales.

A graphic comparison between the durations implied by the estimated DSGE model and those computed from micro data is reported in Figure 2. Along the continuos 45 degree line estimates would match perfectly. Observations marked with a "plus" ("circle") are macro-based durations for which the null hypothesis that their true value equals the micro-based estimate cannot (can) be rejected at the 5 percent significance level. Although there are outliers in all panels, this figure shows that both sets of estimates are in broad quantitative agreement. Furthermore, the figure has many more "pluses" than "circles," meaning that micro and macro estimates are statistically the same for most sectors. This result is remarkable given the large methodological differences between the two approaches.

Notice in Figure 2 that macro estimates are better correlated with micro estimates based on PPI and regular CPI prices than with those based on final CPI prices that include sales. This observation is statistically confirmed in Table 5, where we report the correlation matrix of all duration estimates (Panel A) and results from Ordinary Least Square (OLS) projections of macro estimates on micro ones and an intercept term (Panel B). The correlation between macro estimates and micro estimates based on PPI prices is 0.49 . When one excludes rubber, which is a gross outlier, this correlation increases to 0.65 and is statistically different from zero. The correlation between macro estimates and estimates based regular CPI prices is 0.49 and statistically different from zero. Regression results show that in both cases the slope is positive and statistically different from

\footnotetext{
${ }^{20}$ Nakamura and Steinsson use different sector definitions from ours, so we match the sectors closest in nature. However, they respectively combine primary and fabricated metal, and electric and nonelectric machinery into single categories. Given the ambiguity in matching these sectors, we have dropped them from Table 4.

${ }^{21}$ There were some ELIs for which there was no obvious sectoral match and, consequently, were excluded from the analysis. These were 8 out of 272 ELIs in Nakamura and Steinsson, and 26 out of 350 in Bils and Klenow. Another issue is that the number of ELIs per sector varies considerably. For example, in Bils and Klenow's data, there are 79 ELIs corresponding to food products, but only 2 corresponding to fabricated metal. This means that not all sectoral mean durations are equally accurate. In order the limit the effect of estimates based on too few ELIs, we restricted the analysis to estimates constructed using at least five ELIs. The only exception is tobacco products where cigarettes and cigars account for most of the sectoral output.
} 
zero (although only at the ten percent level for PPI prices), while the intercept is not statistically different from zero.

In contrast, the correlation between macro estimates and final CPI prices, which include sales, is very close to zero and OLS results show a statistically insignificant slope coefficient. These results are not surprising since our model and data abstract from transitory sales. Moreover, these results are consistent with what we observe when we compare micro-based estimates among themselves. The correlation between durations based on PPI and regular CPI prices is high (0.78) and statistically different from zero, ${ }^{22}$ but the correlation between either of them and durations based on final prices is low and not statistically different from zero. ${ }^{23}$

\subsection{Price Adjustment Costs}

We now compute estimates of realized price adjustment costs and compare them with those based on micro data and predicted by other sticky-price models. From the definition of dividends in Equation (13), note that the ratio of price adjustment costs to sectoral revenue in our model is simply $\Phi_{t}^{j}$. By construction, this term is zero in steady state, but an estimate of its average magnitude outside steady state may be computed by means of stochastic simulation. The simulated sample has 1600 observations with innovations drawn from normal distributions but, in order to limit the effect of the initial observation, estimates are computed using only the last 1500 observations. Estimates are reported in Table 6, where we observe that adjustment costs as percent of sectoral revenue range from approximately 0 in, for example, nonelectric machinery to 0.53 in lumber and wood.

The correlation between realized price adjustment costs and the price rigidity estimates reported in the previous section is basically zero (0.04). The reason is that realizations of $\Phi_{t}^{j}$ depend not only on the structural parameter $\phi^{j}$, but also on the size of the price change, $p_{t}^{l j} / p_{t-1}^{l j}$, which is optimally chosen by firms. Thus, for example, realized adjustment costs are somewhat larger in the paper sector (which has an essentially flexible price) than in furniture and fixtures (which has a price duration of five quarters) because price changes are typically larger in the former than in the latter (the median price changes are 1.2 and 0.8 percent, respectively). This means that direct micro estimates of price adjustment costs incurred by firms may not be informative about the structural parameters driving such estimates. One may observe a small ratio of price adjustment costs to revenue precisely because changing prices is so costly, or a large ratio because changing

\footnotetext{
${ }^{22}$ This estimate is similar to the correlation of 0.83 between the frequency of price changes for producer prices and regular consumer prices reported by Nakamura and Steinsson (2008a, p. 19) and computed using 153 goods categories.

${ }^{23}$ Nakamura and Steinsson (2008a) find that sales exhibit different empirical features from regular price changes and so, for example, Kehoe and Midrigan (2007) assume that one-period price discounts involve a smaller menu cost than regular price changes.
} 
prices is a relatively cheap margin for the firm.

Our estimates of realized price adjustment costs are of similar magnitude to those computed by Nakamura and Steinsson (2008b) for the menu-cost and Calvo-plus models (which vary between 0.004 and 0.72 , and between 0.007 and 2.70, respectively), but they are smaller than micro-based estimates by Levy, Bergen, Dutta and Venable (1997), and by Zbaracki, Ritson, Levy, Dutta and Bergen (2004) who find that the cost of changing prices in, respectively, a supermarket and a manufacturing firm are 0.7 and 1.2 percent of revenue. Regarding the former, our estimate for the trade sector (which includes both wholesale and retail trade) is only 0.25 percent of revenue.

\subsection{The Kurtosis of Price Changes}

Since firms in the same sector choose the same adjustment size in a given period, the time series of percental price changes is just the sectoral inflation rate. Furthermore, because the propagation mechanism is linear and shocks are normally distributed, sectoral inflation rates are normally distributed as well, and kurtoses are, therefore, close to 3 (see the second column in Table 6). On the other hand, the distribution of the complete sample of price changes is a mixture of the thirty sectoral distributions. This mixture features fat tails and a kurtosis equal to 6.7, which is quantitatively similar to the estimates of 5.4 and 8.5 reported by Midrigan (2008) for non-sale price changes in the AC Nielsen and Dominick's data sets, respectively.

\subsection{Other Parameter Estimates}

Table 7 reports SMM estimates of the other structural parameters. The estimate of the capital adjustment cost parameter is 4.71 (3.80), where the term in parenthesis is the standard error. This estimate is not statistically different from zero and is quantitatively smaller than values reported in previous literature that estimates $\chi$ using aggregate data alone (see, for example, Kim, 2000, and Bouakez, Cardia and Ruge-Murcia, 2005). On the other hand, our estimate is in line with those reported by Hall (2004) and Cooper and Haltiwanger (2006), which are respectively based on industry- and plant-level data and which imply relatively small capital adjustment costs. In our model, input-output interactions induce strategic complementarity in pricing across sectors and greatly amplify the effects of monetary shocks, thereby reducing the quantitative importance of other real rigidities, like capital adjustment costs. ${ }^{24}$

Labor supply and money demand shocks are relatively persistent and feature volatile innovations, while monetary policy shocks are only mildly persistent and not very volatile. In particular,

\footnotetext{
${ }^{24}$ For analytical results illustrating this amplification mechanism in the context of roundabout models like ours, see Basu (1995).
} 
the estimated autoregressive coefficient is $0.46(0.07)$, which is smaller than, but still consistent with, the estimate that would be obtained from an unrestricted first-order autoregression of the rate of growth of money supply, which is $0.58(0.09){ }^{25}$

The autoregressive coefficient of productivity shocks varies from 0.83 in mining to 0.95 in manufacturing, but the null hypothesis that these values are the same in all sectors cannot be rejected at the 5 percent level. In contrast, there is substantial heterogeneity in the standard deviation of productivity innovations across sectors. Estimates range from 0.02 in services to 0.11 in agriculture and the null hypothesis that standard deviations are the same in all sectors can be rejected at the 5 percent level. In general, productivity innovations in primary sectors (agriculture and mining) are substantially more volatile than in other sectors.

Our results are similar to those in Horvath (2000), who also finds innovations to agriculture and mining to be the most volatile. Horvath estimates the parameters of neutral sectoral productivity shocks from the residuals of outputs minus weighted factor inputs using energy usage to correct for variations in capital utilization. In order to compare the two sets of estimates, notice that the standard deviation of the innovation of Horvath's neutral shock in sector $j$ correspond to $\nu^{j} \sigma_{z^{j}}$ in our model with labor-augmenting shocks. Figure 3 plots the two sets of estimates, with a "plus" ("circle") denoting cases where the null hypothesis that the true value equals the one estimated by Horvath cannot (can) be rejected at the 5 percent significance level. The hypothesis cannot be rejected for 25 of the 30 sectors in our sample but is rejected for oil and gas extraction, paper, leather, metal mining, and tobacco products. In the latter two cases, the hypothesis would not be rejected at the 1 percent level. Finally, the correlation between both sets of estimates is 0.41 and statistically different from zero.

Overall, results reported so far support the idea that our highly disaggregated DSGE model with heterogenous price rigidity captures reasonably well basic features of the micro data, and motivate the policy analysis carried below in Sections 5 through 7 .

\subsection{Model with Identical Price Rigidity Across Sectors}

In this section, we report parameter estimates for a restricted version of the model where price rigidity is the same in all sectors (that is, $\phi^{j}=\phi$ for all $j$ ). Although this restriction is rejected by the data, this model constitutes a useful benchmark to study the contribution of heterogeneity in price rigidity to the propagation of monetary policy shocks.

The estimate of the price rigidity parameter is $\phi=6.48(0.92)$, which implies a duration of 1.58 quarters for prices in all sectors (see Panel B in Table 4). Recall that the median rigidity

\footnotetext{
${ }^{25}$ This estimate was computed by OLS using the rate of growth of M2 for the sample period 1964Q2 to $2002 \mathrm{Q} 4$.
} 
parameter in the heterogeneous model is 4.80, which implies a duration of 1.48 quarters. Both duration estimates (that is, 1.58 and 1.48) are in the ranges of median price durations reported in micro-based studies. For example, the median price duration varies between 1.4 and 1.8 quarters in Bils and Klenow (2004), between 1.2 and 2.4 in Klenow and Kryvtsov (2008), and between 1.4 to 3.6 quarters in Nakamura and Steinsson (2008a).

In turn, all of these estimates are generally smaller than those obtained using aggregate data alone. See, for example, Gali and Gertler (1999), Smets and Wouters (2003), Christiano, Eichenbaum and Evans, (2005), and Bouakez, Cardia and Ruge-Murcia (2005), who respectively report "aggregate" price durations of 5.9, 10.5, 2.5 and 6.5 quarters. Large price rigidity estimates substantially contribute to the empirical success of (one-sector) sticky-price DSGE models but they are now considered implausible in light of the recent evidence on price rigidity at the micro level. As we will see below, our heterogenous, multi-sector DSGE model can reconcile fully-specified macro models with the micro data.

Table 7 reports estimates of the other parameters of the restricted model. They are generally consistent with those obtained for the heterogenous model though, as one would expect, the parameters of the sectoral productivity shocks are more precisely estimated.

\section{Sectoral Effects of Monetary Policy Shocks}

In this Section, we study the effects of a monetary policy shock on sectoral outputs and inflation rates and on relative prices. More precisely, we consider the effects of an innovation that unexpectedly increases the rate of money growth by 1 percent. Thereafter, with innovations set to zero, money growth gradually returns to its steady state at the rate $\rho_{\mu}$. We plot the responses associated with this shock, and examine the relation between the initial sectoral response and several sectoral characteristics using unconditional correlation coefficients and OLS regressions.

The sectoral characteristics are price rigidity (measured by the implied durations reported in Table 4), whether the sector produces a durable good or not, ${ }^{26}$ labor and materials intensity, ${ }^{27}$ the standard deviation of the productivity shock, and the proportion of materials that are purchased from flexible-price producers. For the computation of the latter variable, we classify as flexibleprice producers all sectors for which the null hypothesis that $\phi_{j}=0$ cannot be rejected (see Table 4). Then, for each sector in our sample, we add up the input shares (from the Use Table) of

\footnotetext{
${ }^{26}$ This classification is made following the BLS definition of durability. The durable-good sectors are construction, lumber and wood, furniture and fixtures, primary metal, fabricated metal, nonelectric machinery, electric machinery, transportation equipment, instruments, miscellaneous manufacturing, and stone, clay and glass.

${ }^{27}$ Since production functions exhibit constant returns to scale, intensities are linearly dependent. For this reason we dropped one of them (capital) from the analysis.
} 
those flexible-price sectors. The average sector buys around 60 percent of its materials inputs from flexible-price sectors, but the proportion varies greatly across sectors, ranging from 18 percent in apparel to 88 percent in tobacco products.

\section{$5.1 \quad$ Inflation}

The responses of sectoral inflation rates are plotted as continuos lines in Figure 4. This figure shows that all inflation rates increase following the shock but that there is substantial heterogeneity in the size and dynamics of the sectoral responses. Some sectoral inflations react strongly to the shock but return rapidly to their steady state, while others respond weakly and return slowly and monotonically to their steady state.

The correlation between the magnitude of the initial response of inflation and sectoral characteristics, and the results of an OLS projection of the former on the latter and a constant term, are respectively reported in Panels A and B of Table 8. The correlation between the inflation response and price rigidity is negative, quantitatively large $(-0.8)$ and statistically significant. Thus, as one would expect, sectors with flexible prices (that is, shorter price durations) tend to increase their prices by more than sectors with rigid prices, following an expansionary monetary policy shock.

The correlation with the proportion of materials purchased from flexible-price producers is positive and significant. This result reflects the fact that marginal costs tend to rise by more in sectors whose intermediate inputs have flexible prices. The correlation with materials intensity is negative, although only marginally significant. Thus, sectors that require more materials as productive inputs tend to increase their prices by less after a monetary shock. This mechanism is emphasized by, for example, Basu (1995). However, the latter two correlations are not significant once we control for other factors. In particular, the OLS results in Panel B show that the price rigidity coefficient is statistically significant at the 5 percent level whereas the other coefficients are not. ${ }^{28}$ On the basis of this analysis, we conclude that heterogeneity in price rigidity is the most relevant factor to understand the cross-sectional heterogeneity in sectoral inflation responses to monetary policy shocks.

\subsection{Relative Price Dispersion}

Since the equilibrium is symmetric within sectors but asymmetric across sectors, sectoral relative prices are not all equal to 1 . To avoid ambiguity, we focus on the relative price $\mathrm{p}_{t}^{j}=p_{t}^{j} / P_{t}$, which is also the real price. The distribution of relative prices (not shown) has a mean of 0.90 and a

\footnotetext{
${ }^{28}$ We computed the correlation matrix of the regressors and found that they range from -0.63 to 0.34 . Thus, it is unlikely that these results are driven by collinearity among the explanatory variables.
} 
relatively large standard deviation of 0.28 . Since sectoral inflations react differently to a monetary policy shock, it follows that monetary policy shocks induce changes in the distribution of relative prices. This can be seen in Figure 5 which plots the standard deviation of relative prices following the monetary shock under the heterogenous price rigidity model (see the continuos line). Notice that starting at the steady state value of 0.28 , the standard deviation rises to 0.86 in the quarter following the shock. Hence, there is a large increase in relative price dispersion as a result of the monetary policy shock. This result is primarily due to the strong price response by flexible price producers. Moreover, the effects of monetary policy on relative prices dispersion are long-lived and only after six quarters does the standard deviation approaches the initial one.

In contrast, under the model with identical price rigidity across sectors (see the dotted line), the effect of the monetary policy shock on relative price dispersion is muted and the standard deviation is almost unchanged after the shock.

\subsection{Output}

We now consider the effects of a monetary policy shock on sectoral outputs. The continuos lines in Figure 6 show that sectoral outputs increase following the monetary policy shock. The only exception is tobacco products whose output initially contracts by 0.07 percent but eventually expands after the third quarter. Thus, in general, there is positive output comovement following a monetary shock.

This result contrasts with the prediction of previous two-sector models (see, for example, Ohanian, Stockman and Kilian, 1995, and Barsky, House and Kimball, 2007) where the output of the flexible-price sector contracts, while that of the rigid-price sector expands, after an expansionary monetary policy shock. In a striking example in Barsky, House and Kimball, aggregate output stays unchanged and money is neutral at the aggregate level despite the fact that some prices are sticky. The negative output comovement arises primarily from the absence of inputoutput interactions. The increase in the price of flexible- relative to rigid-price goods leads to a strong substitution effect on the part of households and, therefore, to opposite output effects of monetary policy. As we saw above, in our model, monetary policy shocks also produce changes in relative prices as a result of heterogeneity in price rigidity, but the substitution effect does not drive the output dynamics because firms require the output of other firms to produce their own good. The positive output comovement implied by our multi-sector model is consistent with the empirical evidence reported by Barth and Ramey (2001), Dedola and Lippi (2003) and Peersman and Smets (2005).

Figure 6 also shows considerable heterogeneity in sectoral output responses. Sectors that react 
the least are producers of primary goods (agriculture, metal mining, oil and gas extraction) or basic manufactured commodities (tobacco production and chemicals). The sector that responds the most is construction, followed by lumber and wood, primary metal, transportation equipment, stone, clay and glass, and fabricated metal. Notice that all these sectors are producers of durable goods and that the latter ones are large inputs to construction: the fraction of materials input expenditures by construction that go into lumber and wood, primary metal, and stone, clay and glass, and fabricated metal are 10.3, 2.8, 8.4, and 12.6 respectively, while the proportion of capital input expenditures that goes into transportation equipment is 33.4 percent. This observation suggests that the construction sector plays a prominent role in the transmission of monetary policy through input-output interactions.

The relation between sectoral output responses and sectoral characteristics is reported in Table 8. In Panel A, the correlation between the output response and whether the sector produces a durable good is positive, quantitatively large (0.65) and statistically significant. Thus, producers of durable goods tend to increase their output by more than nondurable good producers following a monetary policy shock. The correlation with the proportion of inputs from flexible-price sectors is negative and statistically significant. The reason is that sectors with a lower proportion of flexibleprice inputs experience a smaller increase in marginal cost following a monetary policy shock and, therefore, have a greater scope to increase their output. The correlation with price rigidity is positive but only marginally significant at the 5 percent level. Thus, as one would expect, sectors with rigid prices tend to increase their output by more than sectors with flexible prices. The correlation with other variables is not statistically different from zero.

In Panel B, OLS results indicate that the coefficients of durability and material intensity are statistically significant at the 5 percent level, while the other coefficients, including those of the proportion of flexible-price inputs and price rigidity, are not significant. We conclude that the most important factor to understand the cross-sectional heterogeneity in sectoral output responses to monetary policy is whether the sector produces a durable good or not. This result is due to the input-output structure of our model and, in particular, to the fact that the general increase in output by all sectors requires an increase in the production of investment goods. Since the production of investment goods is concentrated in relatively small sectors, their output response is proportionally larger than that of other sectors. The implication that durable-good producers react strongly to monetary policy shocks is consistent with the VAR evidence in Barth and Ramey (2001) and Erceg and Levin (2006). 


\section{Aggregate Implications of Sectoral Price Rigidity}

This section examines the implications of heterogeneity in sectoral price rigidity for the nonneutrality of money, cost pass-through, and the volatility and persistence of aggregate variables. It also evaluates the relative contribution of sectoral and aggregate shocks to the unconditional variance of aggregate variables.

\subsection{Aggregate Nonneutrality}

In a recent paper, Carvalho (2006) shows that heterogeneity in price rigidity across sectors amplifies the degree of aggregate monetary nonneutrality. This result is derived analytically in a simple model without capital or intermediate inputs. The purpose of this section is to quantify this amplification effect in the context of our estimated multi-sector model. To do so, we compare the aggregate effects of money in the economies with heterogenous and identical price stickiness along two criteria, namely, the cumulative response of aggregate output to a monetary policy shock and the relative contribution of monetary policy shocks to the variability of aggregate output. Figure 7 depicts the effects of an unexpected monetary expansion on aggregate output and inflation in the heterogenous and symmetric economies. Panel A of this figure shows that the response of aggregate output is larger in magnitude and substantially more persistent in the former than in

the latter. The corresponding cumulative responses, defined as $C R=\sum_{k=0}^{p} \hat{y}_{t+k}$, are 13.07 and 2.13, respectively, where $p$ is the horizon beyond which $C R$ remains invariant. ${ }^{29}$ Thus, heterogeneity in price stickiness increases monetary nonneutrality by a factor of 6 in our model. In contrast, there is little difference in the response of aggregate inflation across the two economies, as shown in Panel B of Figure 7 .

Table 10 shows that monetary policy shocks explain roughly 25 percent of the unconditional variance of output in the economy with heterogenous price rigidity but that this fraction drops to less than 5 percent in the economy characterized by the identical price rigidity across sectors. A similar result is reported by Nakamura and Steinsson (2008b), who find that monetary policy shocks account for about one third of output fluctuations.

\subsection{Cost Pass-Through}

An important issue in macroeconomics is the extent to which, and the speed at which, changes in marginal costs are reflected in prices. This notion is commonly referred to as cost pass-through. In this section, we measure the degree of pass-through from sectoral marginal costs to the aggregate

\footnotetext{
${ }^{29}$ In practice, we set $p=300$.
} 
price index, that is, the CPI. To this end, we adopt an analogous definition to that proposed by Bouakez and Rebei (2008) to measure exchange rate pass-through. We define cost pass-through at horizon $\tau$ as

$$
\mathcal{P}_{t+\tau}=\frac{\operatorname{Cov}_{t-1}\left(\hat{P}_{t+\tau}, \hat{\Psi}_{t+\tau}^{j}\right)}{\operatorname{Var}_{t-1}\left(\hat{\Psi}_{t+\tau}^{j}\right)},
$$

where $\Psi_{t}$ is the nominal marginal cost and the circumflex denotes deviation from trend. This definition has several advantages over the conventional approach of measuring pass-through as the regression coefficient of inflation on changes in the marginal cost in a single-equation framework. First, this definition expresses pass-through as a time-varying coefficient that depends on the horizon, rather than as a static elasticity. Second, because it involves (time) conditional rather than unconditional covariances, this definition does nor suffer from the endogeneity problem arising from the fact that costs and prices are simultaneously determined. Finally, expression (34) can be related in an intuitive manner to the dynamic responses of the sectoral marginal costs and the CPI to each of the structural shocks. To see this, note that (34) can be written as

$$
\mathcal{P}_{t+\tau}=\frac{\sum_{s} \sum_{h=0}^{\tau} \omega_{s, h} \varkappa_{s, h} \sigma_{s}^{2}}{\sum_{s} \sum_{h=0}^{\tau} \varkappa_{s, h}^{2} \sigma_{s}^{2}}=\sum_{s} \sum_{h=0}^{\tau} \frac{\omega_{s, h}}{\varkappa_{s, h}}\left(\frac{\varkappa_{s, \tau}^{2} \sigma_{s}^{2}}{\sum_{s} \sum_{h=0}^{\tau} \varkappa_{s, \tau}^{2} \sigma_{s}^{2}}\right),
$$

where $s$ is a subscript that runs across all structural shocks and $\omega_{s, h}$ and $\varkappa_{s, h}$ are, respectively, the impulse response functions of $\hat{P}$ and $\hat{\Psi}^{j}$ at horizon $h$ following shock $s$. The ratios $\omega_{s, h} / \varkappa_{s, h}$ are interpreted as conditional pass-through coefficients. To gain some intuition into the relationship between unconditional and conditional measures of pass-through, it is useful to focus on what happens at time $t$ (i.e., when $\tau=0$ ). In this case, we have

$$
\mathcal{P}_{t}=\sum_{s} \frac{\omega_{s, 0}}{\varkappa_{s, 0}} \frac{\varkappa_{s, 0}^{2} \sigma_{s}^{2}}{\sum_{s} \varkappa_{s, 0}^{2} \sigma_{s}^{2}} .
$$

That is, unconditional pass-through at time $t$ is equal to the sum of conditional pass-through coefficients $\left(\omega_{s, 0} / \varkappa_{s, 0}\right)$ weighted by the contribution of each shock to the (conditional) variance of the nominal marginal cost at time $t$. Equation (35) makes it clear that cost-pass-through is a function of the structural parameters of the economy.

Figure 8 depicts unconditional measures of pass-through from the marginal cost in each sector to the CPI under the heterogenous and identical price rigidity models. In both cases, pass-through is incomplete in the short run and converges monotonically to its long run value of 100 percent. The figure shows that there is large heterogeneity in the degree of pass-through originating from 
the different sectors even when sectors are characterized by the same amount of price rigidity. In order to understand these results, it is useful to further develop expression (36) by substituting in the definition of the CPI. This yields

$$
\mathcal{P}_{t+\tau}=\xi^{j} \frac{\operatorname{Cov}_{t-1}\left(\hat{P}_{t+\tau}^{j}, \hat{\Psi}_{t+\tau}^{j}\right)}{\operatorname{Var}_{t-1}\left(\hat{\Psi}_{t+\tau}^{j}\right)}+\sum_{i \neq j}^{J}\left(\xi^{i} \frac{\operatorname{Cov}_{t-1}\left(\hat{P}_{t+\tau}^{i}, \hat{\Psi}_{t+\tau}^{j}\right)}{\operatorname{Var}_{t-1}\left(\hat{\Psi}_{t+\tau}^{j}\right)}\right) .
$$

Equation (37) shows that cost pass-through to the CPI consists of two components. First, the term $\operatorname{Cov}_{t-1}\left(\hat{P}_{t+\tau}^{j}, \hat{\Psi}_{t+\tau}^{j}\right) / \operatorname{Var}_{t-1}\left(\hat{\Psi}_{t+\tau}^{j}\right)$ measures the pass-through from the marginal cost of a given sector to its price. This term depends primarily on the degree of price rigidity in that sector: ${ }^{30}$ the more rigid the sectoral price, the less responsive it will be to changes in the marginal cost and the lower the degree of cost pass-through. This intuition is confirmed by Figure 9, which shows cost pass-through to the price in each sector. In the case of heterogenous price rigidity, short-run pass-through is complete in sectors that have fully flexible prices and is relatively low in sectors that have relatively rigid prices. Price rigidity also affects cost-pass-through to sectoral prices indirectly by changing the relative importance of shocks in explaining the variance of the sectoral marginal cost. This is why sectors exhibit different degrees of pass-through even when their prices are equally rigid.

Second, the term $\operatorname{Cov}_{t-1}\left(\hat{P}_{t+\tau}^{i}, \hat{\Psi}_{t+\tau}^{j}\right) / \operatorname{Var}_{t-1}\left(\hat{\Psi}_{t+\tau}^{j}\right)$ measures the pass-through from the marginal cost of a given sector to the price of another sector. The second term on the right-hand side of equation (37) is therefore affected by the degree of price rigidity in all the remaining sectors of the economy, which explains why the pass-through from sectoral marginal costs to the CPI is quite low even for sectors that have fully flexible prices.

Figure 8 also shows that, in the short run, cost pass-through is almost always lower under heterogenous than under identical price stickiness (the only two exceptions being agriculture and construction). In several cases, the difference between the two measures is quite large. This shows that sectoral heterogeneity in price rigidity amplifies the overall degree of nominal rigidity in the economy and implies that failing to account for this heterogeneity may lead to a substantial mismeasurement of the degree of cost pass-through.

\subsection{Aggregate Persistence and Volatility}

The persistence and volatility of aggregate output and inflation predicted by the models with heterogeneous and identical price rigidity are computed by means of simulation and are reported in Table 9. Persistence is measured by the sum of autocorrelation coefficients selected using

\footnotetext{
${ }^{30}$ This is so in both of our models because we abstract from fixed costs and changes in the desired markup, which would arise from a time-varying elasticity of demand.
} 
the Modified Information Criterion in $\mathrm{Ng}$ and Perron (2001) and volatility is measured by the unconditional standard deviation of the simulated series.

For the heterogeneous rigidity model, aggregate inflation persistence is 0.51 , which is larger than that of the median sector $(0.21)$ and relatively close to that found in U.S. data (0.71). In contrast, for the model with identical price rigidity across sectors, aggregate inflation persistence is equal to that of the median sector, which is only 0.25 . This result suggests that sectoral heterogeneity in price stickiness substantially increases the predicted persistence of aggregate inflation. This is important because existing models based on forward-looking pricing rules usually predict lower inflation persistence than in the data and, as a strategy to address this shortcoming, assume an indexation mechanism whereby rule-of-thumb firms fix their prices as a function of past inflation (see, among others, Gali and Gertler, 1999, and Christiano, Eichenbaum and Evans, 2005). Instead, in our model, the increased inflation persistence is due to the aggregation of sectoral inflation rates with different degrees of persistence. ${ }^{31}$ This heterogeneity is a prominent feature of the data and, with the help of our model, we explain it below in terms of underlying sectoral characteristics (see Section 7.1 below). Regarding output persistence, estimates are similar in both models and quite close to that in U.S. data.

Finally, Table 9 shows that aggregate variables are considerably less volatile than the median sector in both models. While inflation volatility is quantitatively close that of U.S. CPI inflation (especially for the heterogeneous rigidity model), both models tend to overpredict output volatility.

\subsection{Variance Decomposition}

Table 10 reports the contribution of the different shocks to the unconditional variance of aggregate output and inflation. ${ }^{32}$ In the model with heterogenous rigidity, sectoral productivity shocks play a limited role in explaining the unconditional variance of aggregate variables. Monetary policy shocks account for most of the variance of inflation (72 percent), while labor supply shocks account for most of the variance of output (64 percent). However, monetary policy shocks still explain a significant part (around 24 percent) of output variability. This result is in line with empirical results reported by Shapiro and Watson (1988) and Nakamura and Steinsson (2008b) who find that nominal shocks account respectively for 28 and 26 percent of output variations. In constrast, the model with identical price rigidity in all sectors predicts a large role for sectoral productivity shocks in output fluctuations and a negligible role for monetary policy (approximately 5 percent).

\footnotetext{
${ }^{31}$ The importance of aggregation in explaining the observed persistence of CPI inflation is also noted by Clark (2006) and Altissimo, Mojon and Zaffaroni (2007).

${ }^{32}$ Examples of previous papers that study the relative importance of aggregate versus sectoral shocks in the context of real business cycle models include Long and Plosser (1983, 1987), Dupor (1999), Horvath (2000) and Carvalho (2008).
} 


\section{The Importance of Sectoral Shocks}

The purpose of this sections is to show that sectoral shocks are crucial to understand the behavior of the micro data. In particular, sectoral shocks are an important contributor to the persistence and volatility of sectoral output and inflation and account for a significant part of the unconditional variance of relative prices and marginal costs.

\subsection{Sectoral Persistence and Volatility}

The persistence and volatility of sectoral outputs and inflation rates are reported in Table 11. From this table, it is clear that there is limited heterogeneity in sectoral output persistence. The distribution only ranges from 0.83 in lumber and wood to 0.97 in tobacco products, is negatively skewed, and has a relatively high median of 0.93. In contrast, there is large heterogeneity in sectoral inflation persistence, ranging from -0.16 in FIRE to 0.90 in apparel. The distribution is bimodal as a result of the mixture of one distribution for flexible-price sectors and another one for rigid-price sectors. Finally, inflation persistence in the median sector is 0.21 , which as we saw above, is much less than the persistence of aggregate inflation (0.51).

We examine the relation between persistence and sectoral characteristics using correlations and OLS regressions and report results in Table 12. The correlation between output persistence and durability is negative, quantitatively large $(-0.61)$ and statistically significant. The correlation with the proportion of materials purchased from flexible-price producers is positive but only marginally significant. Furthermore, when we control for other sectoral characteristics in the OLS regression, only the coefficient of durability is statistically significant. We conclude that output of durable-good producers is generally less persistent than that of nondurable producers.

The correlation between inflation persistence and price rigidity is positive (0.89) and statistically significant, meaning that sectors with rigid prices (that is, with longer price durations) feature more persistent inflation rates than sectors with flexible prices. The correlation with the proportion of materials purchased from flexible-price producers is negative $(-0.68)$ and statistically significant. Thus, the lower inflation persistence on the part of flexible-price producers, translates into less persistent marginal cost and, hence, the less persistent inflation of their customers. However, the latter result is not robust to controlling for other factors: in the OLS regression, the only statistically significant coefficient is that of price rigidity.

Regarding volatility, Table 11 shows heterogeneity in both sectoral outputs and inflation rates

with both distributions mildly positively skewed. The correlations and regressions in Table 12 indicate that price rigidity and durability are respectively important to understand the cross- 
sectional variation in inflation and output volatilities. However, the standard deviation of the sector-specific productivity shocks is also important to account for the heterogeneity in sectoral outputs and inflation rates: the correlations are, respectively, 0.37 and 0.41 , both are statistically different from zero, and robust to controlling for other sectoral characteristics. These results strongly suggest the importance of sectoral shocks on the volatility of sectoral variables and motivate the more detailed quantitative analysis that follows.

\subsection{Variance Decomposition}

This section examines the relative importance of sector-specific shocks in accounting for the unconditional variance of sectoral inflation, relative prices, marginal costs and output. In particular, Table 13 reports the proportion of the unconditional variance of each series that is accounted for by the productivity shock to its own sector.

Consider first sectoral inflation. The idiosyncratic productivity shock accounts for a large part of the unconditional variance of sectoral inflation in agriculture, mining and manufacturing, but plays a smaller role in construction and services. Using statistical factor models, Boivin, Giannoni and Mihov (2007), and Mackowiak, Moench and Wiederholt (2008) also find that sector-specific conditions are the most important determinants of sectoral inflation rates. However, it is important to note that in our model, productivity shocks to other sectors may be quantitatively important as a result of input-output interactions. For example, the proportion of sectoral inflation in food products that is explained by its own productivity shock is only 8.1 percent, but that explained by the productivity shock in agriculture is 25 percent. This result is, of course, due to the fact that agricultural goods are a major input in food production, accounting for 38 percent of the materials expenditures by that sector.

Consider now sectoral relative prices and marginal costs. Except for services, the idiosyncratic productivity shock explains an extremely large proportion of the unconditional variance of these series. For example, it explains 98 percent of the unconditional variance of the marginal cost in agriculture, 85 percent in coal, 21 percent in construction, 75 percent in apparel, and 70 percent in chemicals. As before, shocks to other sectors, which are either large suppliers or consumers, are important in some cases. For instance, in the case of tobacco products and oil refining, 14 percent of the variance of their marginal costs are explained, respectively, by shocks to agriculture and to oil and gas extraction.

These results show that sectoral shocks are essential to interpret observed features of the micro data. In particular, they suggest that sectoral shocks are an important cause of the price changes observed at the micro level and explain the empirical observation (see Klenow and Kryvtsov, 2008) 
that average price changes, measured by the percentage change in the CPI, are very small compared with individual price changes.

\section{Conclusions}

This paper constructs and estimates a highly disaggregated, multi-sector DSGE model where sectors are heterogenous in production functions, price rigidity and the combination of materials and investment inputs employed in their production processes. These features are prominent in the data and, as we show, are crucial to understand the dynamics of aggregate and sectoral variables following a monetary policy shock. Relaxing the assumption of symmetry in standard models, allows us to explore the effects of aggregate and sectoral shocks at both the aggregate and sectoral levels. This, combined with the very disaggregated nature of our analysis means that we can successfully bridge two large strands of the literature in Macroeconomics: the one based on DSGE models and the one that directly studies the statistical properties of the micro data. Our multisector setup allows us to get as close as one possibly can to the micro data, while preserving the theoretical advantages of the fully-specified DSGE framework.

The main findings of this research are the following:

1. Monetary policy shocks generate heterogenous effects on sectoral output and inflation but via different mechanisms.

As was documented in Figures 4 and 6, there are large differences in the responses of sectoral output and inflation to monetary policy shocks. The statistical analysis reported in Table 8 suggests that the heterogeneity in sectoral inflation responses is primarily driven by heterogeneity in price stickiness. Intuitively, inflation in sectors with flexible prices tend increase more than in sectors with rigid prices after an expansionary monetary policy shock.

In contrast, the heterogeneity in sectoral output responses is driven by durability: durablegood sectors increase their output by more than nondurable-goods sector and this is so regardless of whether their prices are flexible or rigid. The sector whose output increases the most following an expansionary monetary policy shock is construction, followed by sectors that are large inputs to construction (for example, lumber and wood and primary metal products). This result indicates that the construction sector may play a prominent role in the transmission of monetary policy via input-output interactions.

Overall, the large output effects of monetary policy in the durable-good sectors are driven by the sparsity of the U.S. Capital Flow Table. The production of durable goods is concentrated in relatively small sectors. For example, all buildings and structures in the U.S. economy are produced by the construction sector which accounts for only 5 percent of the total value added. 
This concentration means that an increase in demand for capital goods by households and firms is associated with a large output increase in these sectors.

2. Monetary policy shocks generate large and persistent effects on relative prices.

As documented in Figure 5, the heterogenous inflation responses to monetary policy shocks lead to large changes in the distribution of relative prices. The welfare effects of these price changes may be potentially large and have important implications for the design of monetary policy. For example, in one-sector models, optimal monetary policy involves stabilizing the aggregate price level, but research by Aoki (2001), Benigno (2004), Huang and Liu (2005), and Erceg and Levin (2006) indicates that this strategy may be sub-optimal in an economy where sectors are characterized by different degrees of nominal rigidity.

3. Heterogeneity in price rigidity is a powerful amplification mechanism for monetary policy shocks.

Even though the median price rigidity is the same in the models with heterogenous and identical price rigidity across sectors, the former generates much larger monetary policy effects than the latter. Carvalho (2006) and Nakamura and Steinsson (2008b) find similar results but under more stringent assumptions (for example, no capital). This paper shows that the importance of heterogeneity in price rigidity carries through in more general environments and that heterogeneity generates substantial inflation persistence and nontrivial implications for cost pass-through.

4. Sectoral shocks are crucial to understand sectoral dynamics.

Our empirical results indicate that sectoral shocks are crucial to explain the dynamics of sectoral output and inflation. Klenow and Kryvtsov (2008) conjecture the importance of sector-specific shocks to reconcile the highly volatile sectoral inflation rates with the smoother aggregate rate. Statistical models in Boivin, Giannoni and Mihov (2007) and Mackowiak, Moench and Wiederholt (2008) show that changes in sector-specific conditions are important determinants of sectoral inflation rates. Our fully-specified DSGE model provides a structural explanation for those empirical results but, in addition, it shows that sector-specific productivity shocks also account for a substantial proportion of the volatility of sectoral output, marginal costs and relative prices, and that shocks specific to one sector may have quantitatively large effects on other sectors through input-output interactions. 
Table 1. Sectors

\begin{tabular}{|c|c|c|}
\hline & $\begin{array}{c}\text { SIC } \\
\text { Codes }\end{array}$ & $\begin{array}{c}\text { Consumption } \\
\text { Weights }\end{array}$ \\
\hline Agriculture & $01-09$ & 0.02 \\
\hline Metal Mining & 10 & 0.01 \\
\hline Coal Mining & 12 & 0.01 \\
\hline Oil and Gas Extraction & 13 & 0.01 \\
\hline Nonmetallic Mining & 14 & 0.01 \\
\hline Construction & $15-17$ & 0.01 \\
\hline Food Products & 20 & 0.12 \\
\hline Tobacco Products & 21 & 0.01 \\
\hline Textile Mill Products & 22 & 0.01 \\
\hline Apparel & 23 & 0.04 \\
\hline Lumber and Wood & 24 & 0.01 \\
\hline Furniture and Fixtures & 25 & 0.02 \\
\hline Paper & 26 & 0.02 \\
\hline Printing and Publishing & 27 & 0.01 \\
\hline Chemicals & 28 & 0.03 \\
\hline Oil Refining & 29 & 0.03 \\
\hline Rubber and Plastics & 30 & 0.01 \\
\hline Leather & 31 & 0.01 \\
\hline Stone, Clay and Glass & 32 & 0.01 \\
\hline Primary Metal & 33 & 0.01 \\
\hline Fabricated Metal & 34 & 0.01 \\
\hline Nonelectric Machinery & 35 & 0.01 \\
\hline Electric Machinery & 36 & 0.02 \\
\hline Transportation Equip. & 37 & 0.05 \\
\hline Instruments & 38 & 0.01 \\
\hline Misc. Manufacturing & 39 & 0.01 \\
\hline Transport and Utilities & $40-49$ & 0.21 \\
\hline Trade & $50-59$ & 0.25 \\
\hline FIRE & $60-67$ & 0.01 \\
\hline Other Services & $70-87$ & 0.01 \\
\hline
\end{tabular}

Notes: FIRE stands for finance, insurance and real estate. The consumption weights are based on Horvath (2000, p. 87) 
Table 2. Production Function Parameters

\begin{tabular}{|c|c|c|c|c|c|c|}
\hline \multirow[b]{2}{*}{ Sector } & \multicolumn{2}{|l|}{$\nu^{j}$} & \multicolumn{2}{|l|}{$\alpha^{j}$} & \multicolumn{2}{|c|}{$\gamma^{j}$} \\
\hline & Estimate & s.e & Estimate & s.e & Estimate & s.e \\
\hline Agriculture & $0.261^{*}$ & 0.006 & $0.142^{*}$ & 0.005 & $0.597^{*}$ & 0.006 \\
\hline Metal Mining & $0.328^{*}$ & 0.011 & $0.306^{*}$ & 0.015 & $0.366^{*}$ & 0.024 \\
\hline Coal Mining & $0.432^{*}$ & 0.009 & $0.194^{*}$ & 0.008 & $0.374^{*}$ & 0.010 \\
\hline Oil and Gas Extraction & $0.176^{*}$ & 0.004 & $0.456^{*}$ & 0.009 & $0.368^{*}$ & 0.011 \\
\hline Nonmetallic Mining & $0.314^{*}$ & 0.004 & $0.254^{*}$ & 0.006 & $0.432^{*}$ & 0.009 \\
\hline Construction & $0.394^{*}$ & 0.004 & $0.052^{*}$ & 0.001 & $0.554^{*}$ & 0.005 \\
\hline Food Products & $0.161^{*}$ & 0.002 & $0.084^{*}$ & 0.005 & $0.755^{*}$ & 0.006 \\
\hline Tobacco Products & $0.146^{*}$ & 0.005 & $0.290^{*}$ & 0.018 & $0.564^{*}$ & 0.021 \\
\hline Textile Mill Products & $0.229^{*}$ & 0.004 & $0.067^{*}$ & 0.002 & $0.704^{*}$ & 0.005 \\
\hline Apparel & $0.325^{*}$ & 0.005 & $0.060^{*}$ & 0.003 & $0.615^{*}$ & 0.007 \\
\hline Lumber and Wood & $0.247^{*}$ & 0.004 & $0.100^{*}$ & 0.003 & $0.653^{*}$ & 0.003 \\
\hline Furniture and Fixtures & $0.365^{*}$ & 0.003 & $0.079^{*}$ & 0.002 & $0.557^{*}$ & 0.003 \\
\hline Paper & $0.261^{*}$ & 0.002 & $0.136^{*}$ & 0.003 & $0.603^{*}$ & 0.003 \\
\hline Printing and Publishing & $0.398^{*}$ & 0.004 & $0.124^{*}$ & 0.003 & $0.478^{*}$ & 0.006 \\
\hline Chemicals & $0.237^{*}$ & 0.003 & $0.183^{*}$ & 0.004 & $0.581^{*}$ & 0.006 \\
\hline Oil Refining & $0.091^{*}$ & 0.005 & $0.103^{*}$ & 0.004 & $0.806^{*}$ & 0.008 \\
\hline Rubber and Plastics & $0.323^{*}$ & 0.002 & $0.091^{*}$ & 0.002 & $0.586^{*}$ & 0.002 \\
\hline Leather & $0.326^{*}$ & 0.005 & $0.089^{*}$ & 0.007 & $0.585^{*}$ & 0.003 \\
\hline Stone, Clay and Glass & $0.369^{*}$ & 0.004 & $0.125^{*}$ & 0.004 & $0.507^{*}$ & 0.002 \\
\hline Primary Metal & $0.229^{*}$ & 0.003 & $0.084^{*}$ & 0.002 & $0.687^{*}$ & 0.004 \\
\hline Fabricated Metal & $0.346^{*}$ & 0.002 & $0.104^{*}$ & 0.003 & $0.549^{*}$ & 0.003 \\
\hline Nonelectric Machinery & $0.361^{*}$ & 0.004 & $0.112^{*}$ & 0.002 & $0.527^{*}$ & 0.003 \\
\hline Electric Machinery & $0.350^{*}$ & 0.005 & $0.127^{*}$ & 0.006 & $0.523^{*}$ & 0.003 \\
\hline Transportation Equip. & $0.283^{*}$ & 0.004 & $0.080^{*}$ & 0.004 & $0.637^{*}$ & 0.003 \\
\hline Instruments & $0.460^{*}$ & 0.006 & $0.100^{*}$ & 0.003 & $0.440^{*}$ & 0.005 \\
\hline Misc. Manufacturing & $0.327^{*}$ & 0.005 & $0.117^{*}$ & 0.007 & $0.555^{*}$ & 0.006 \\
\hline Transport and Utilities & $0.314^{*}$ & 0.005 & $0.248^{*}$ & 0.004 & $0.437^{*}$ & 0.009 \\
\hline Trade & $0.500^{*}$ & 0.005 & $0.148^{*}$ & 0.002 & $0.352^{*}$ & 0.007 \\
\hline FIRE & $0.283^{*}$ & 0.004 & $0.356^{*}$ & 0.006 & $0.361^{*}$ & 0.005 \\
\hline Other Services & $0.427^{*}$ & 0.002 & $0.195^{*}$ & 0.005 & $0.378^{*}$ & 0.006 \\
\hline
\end{tabular}

Note: s.e. denotes standard error and $*$ denotes significance at the 5 percent level. 


\section{Table 3. Correlation between Commodity-Based}

and Industry-Level Inflation

\begin{tabular}{lc}
\hline \hline \multicolumn{1}{c}{ Sector } & Correlation \\
\hline & \\
Agriculture & $n . a$. \\
Coal Mining & $0.940^{*}$ \\
Oil and Gas Extraction & $0.586^{*}$ \\
Nonmetallic Mining & $0.687^{*}$ \\
Food Products & $0.857^{*}$ \\
Tobacco Products & $0.998^{*}$ \\
Lumber and Wood & $0.981^{*}$ \\
Furniture and Fixtures & $0.753^{*}$ \\
Paper & $0.964^{*}$ \\
Chemicals & $0.923^{*}$ \\
Oil Refining & $0.998^{*}$ \\
Rubber and Plastics & $0.963^{*}$ \\
Leather & $0.646^{*}$ \\
Stone, Clay and Glass & $0.881^{*}$ \\
& \\
\hline
\end{tabular}

Notes: $*$ denotes significance at the 5 percent level. The statistic used to test the null hypothesis that the correlation is zero is computed as $R \sqrt{T-2} / \sqrt{1-R}$ where $R$ is the correlation coefficient and $T$ is the sample size. Under the null, this statistic follows a $t$ distribution with $T-2$ degrees of freedom (see Hogg and Craig, 1978, pp. 300-301). The sample period used to compute these correlations is 1986Q2 to 2002Q4 for coal, oil and natural gas, and oil refining, and 1985Q2 to 2002Q4 for the other sectors. We were unable to compute the correlation for agriculture because no industry-level PPI is produced for this sector by the BLS. 
Table 4. Sectoral Price Rigidities

\begin{tabular}{|c|c|c|c|c|c|c|c|c|}
\hline \multirow[b]{3}{*}{ Sector } & \multirow{2}{*}{\multicolumn{4}{|c|}{$\phi^{j}$}} & \multicolumn{4}{|c|}{ Duration in Micro Data } \\
\hline & & & & & \multicolumn{3}{|c|}{ NS } & \multirow{2}{*}{$\begin{array}{c}\text { BK } \\
\text { CPI } \\
\text { Final }\end{array}$} \\
\hline & Estimate & s.e. & $\begin{array}{c}\text { Implied } \\
\text { Probability }\end{array}$ & $\begin{array}{c}\text { Implied } \\
\text { Duration }\end{array}$ & PPI & $\begin{array}{c}\text { CPI } \\
\text { Regular }\end{array}$ & $\begin{array}{c}\text { CPI } \\
\text { Final }\end{array}$ & \\
\hline & \multicolumn{4}{|c|}{ A. Heterogeneous Rigidity } & & & & \\
\hline Agriculture & 0.001 & 2.10 & 0.000 & 1.00 & 0.38 & 1.91 & 1.32 & 1.20 \\
\hline Metal Mining & 4.81 & 7.46 & 0.319 & 1.47 & & & & \\
\hline Coal Mining & 2.80 & 5.80 & 0.235 & 1.31 & & & & \\
\hline Oil and Gas Extraction & 0.056 & 7.07 & 0.008 & 1.01 & & & & \\
\hline Nonmetallic Mining & $81.42^{*}$ & 9.51 & 0.748 & 3.96 & & & & \\
\hline Construction & $140.7^{*}$ & 7.69 & 0.802 & 5.04 & & & & \\
\hline Food Products & $189.9^{*}$ & 7.96 & 0.827 & 4.77 & 1.25 & 3.21 & 1.55 & 1.11 \\
\hline Tobacco Products & 0.001 & 1.81 & 0.000 & 1.00 & & 1.34 & 0.88 & 1.40 \\
\hline Textile Mill Products & $13.78^{*}$ & 5.48 & 0.498 & 1.99 & & & & \\
\hline Apparel & $666.7^{*}$ & 7.90 & 0.904 & 10.41 & 9.01 & 10.18 & 0.87 & 0.91 \\
\hline Lumber and Wood & $70.88^{*}$ & 4.90 & 0.732 & 3.73 & 7.58 & & & \\
\hline Furniture and Fixtures & $158.3^{*}$ & 12.09 & 0.812 & 5.31 & 5.85 & 6.29 & 1.35 & 1.29 \\
\hline Paper & 1.46 & 1.97 & 0.151 & 1.18 & 3.55 & & & \\
\hline Printing and Publishing & $24.72^{*}$ & 8.21 & 0.592 & 2.45 & & 6.55 & 4.94 & 5.39 \\
\hline Chemicals & 0.199 & 0.95 & 0.027 & 1.02 & 2.95 & 4.25 & 2.23 & 2.08 \\
\hline Oil Refining & 1.80 & 8.23 & 0.175 & 1.21 & 0.68 & 0.26 & 0.24 & 0.20 \\
\hline Rubber and Plastics & 4.79 & 2.76 & 0.318 & 1.47 & 8.33 & & & \\
\hline Leather & $330.7^{*}$ & 5.04 & 0.866 & 7.46 & 5.21 & 9.62 & 1.12 & 1.13 \\
\hline Stone, Clay and Glass & 21.33 & 14.01 & 0.569 & 2.32 & 5.46 & & & \\
\hline Primary Metal & $507.5^{*}$ & 16.94 & 0.890 & 9.13 & & & & \\
\hline Fabricated Metal & 0.009 & 1.62 & 0.001 & 1.00 & & & & \\
\hline Nonelectric Machinery & 0.001 & 3.00 & 0.000 & 1.00 & & 5.45 & 1.98 & 1.31 \\
\hline Electric Machinery & 0.005 & 5.69 & 0.001 & 1.00 & & 4.59 & 1.59 & 1.35 \\
\hline Transportation Equip. & $42.75^{*}$ & 14.56 & 0.670 & 2.03 & 0.74 & 3.02 & 2.61 & 0.80 \\
\hline Instruments & 0.001 & 12.80 & 0.000 & 1.00 & & 6.05 & 2.03 & 3.11 \\
\hline Misc. Manufacturing & 4.29 & 4.08 & 0.301 & 1.43 & 2.02 & 9.14 & 2.43 & 1.76 \\
\hline Transport and Utilities & $151.1^{*}$ & 13.30 & 0.808 & 5.20 & & 1.67 & 1.66 & 2.11 \\
\hline Trade & $423.8^{*}$ & 10.73 & 0.881 & 8.38 & & 6.70 & 6.40 & 3.65 \\
\hline FIRE & 0.004 & 1.92 & 0.000 & 1.00 & & & & 2.00 \\
\hline \multirow[t]{2}{*}{ Other Services } & 0.305 & 1.71 & 0.040 & 1.04 & & 5.81 & 5.63 & 4.10 \\
\hline & \multicolumn{4}{|c|}{ B. Identical Rigidity } & & & & \\
\hline All Sectors & $6.48^{*}$ & 0.92 & 0.631 & 1.58 & & & & \\
\hline
\end{tabular}

Note: * denotes significance at the 5 percent level. 
Table 5. Relation with Micro Estimates

\begin{tabular}{|c|c|c|c|c|}
\hline & \multicolumn{3}{|c|}{ NS } & \multirow{3}{*}{$\begin{array}{c}\text { BK } \\
\text { CPI } \\
\text { Final }\end{array}$} \\
\hline & \multirow[b]{2}{*}{ PPI } & CPI & CPI & \\
\hline & & Regular & Final & \\
\hline & \multicolumn{4}{|c|}{ A. Correlations } \\
\hline DSGE Model & $0.49^{\dagger}$ & $0.49^{*}$ & 0.04 & -0.09 \\
\hline NS PPI & 1.00 & $0.78^{*}$ & -0.28 & 0.08 \\
\hline NS CPI Regular & & 1.00 & 0.26 & 0.25 \\
\hline NS CPI Final & & & 1.00 & $0.84^{*}$ \\
\hline \multirow[t]{2}{*}{ BK CPI Final } & & & & 1.00 \\
\hline & \multicolumn{4}{|c|}{ B. OLS } \\
\hline Intercept & 1.48 & 0.81 & $3.22^{*}$ & $3.67^{*}$ \\
\hline & $(1.05)$ & (1.17) & $(1.51)$ & $(1.33)$ \\
\hline NS PPI & $\begin{array}{c}0.50^{\dagger} \\
(0.28)\end{array}$ & & & \\
\hline NS CPI Regular & & $0.51^{*}$ & & \\
\hline & & $(0.26)$ & & \\
\hline NS CPI FInal & & & 0.08 & \\
\hline & & & $(0.55)$ & \\
\hline BK CPI Final & & & & -0.21 \\
\hline & & & & $(0.51)$ \\
\hline R Squared & 0.21 & 0.24 & 0.00 & 0.00 \\
\hline
\end{tabular}

Note: $*$ and $\dagger$ respectively denote significance at the 5 and 10 percent levels. 
Table 6. Other Micro Implications

\begin{tabular}{|c|c|c|}
\hline & Cost & Kurtosis \\
\hline \multicolumn{3}{|l|}{ Sector } \\
\hline Agriculture & 0.32 & 2.77 \\
\hline Metal Mining & 0.00 & 2.95 \\
\hline Coal Mining & 0.12 & 2.96 \\
\hline Oil and Gas Extraction & 0.13 & 2.95 \\
\hline Nonmetallic Mining & 0.00 & 2.95 \\
\hline Construction & 0.29 & 3.02 \\
\hline Food Products & 0.26 & 2.91 \\
\hline Tobacco Products & 0.27 & 2.98 \\
\hline Textile Mill Products & 0.00 & 3.02 \\
\hline Apparel & 0.09 & 3.04 \\
\hline Lumber and Wood & 0.53 & 3.13 \\
\hline Furniture and Fixtures & 0.22 & 2.82 \\
\hline Paper & 0.29 & 3.08 \\
\hline Printing and Publishing & 0.02 & 3.33 \\
\hline Chemicals & 0.18 & 2.92 \\
\hline Oil Refining & 0.01 & 3.04 \\
\hline Rubber and Plastics & 0.03 & 3.08 \\
\hline Leather & 0.07 & 2.99 \\
\hline Stone, Clay and Glass & 0.35 & 2.97 \\
\hline Primary Metal & 0.17 & 3.02 \\
\hline Fabricated Metal & 0.32 & 3.04 \\
\hline Nonelectric Machinery & 0.00 & 3.08 \\
\hline Electric Machinery & 0.00 & 2.98 \\
\hline Transportation Equip. & 0.00 & 3.14 \\
\hline Instruments & 0.16 & 2.96 \\
\hline Misc. Manufacturing & 0.00 & 3.12 \\
\hline Transport and Utilities & 0.05 & 2.98 \\
\hline Trade & 0.25 & 3.13 \\
\hline FIRE & 0.39 & 2.99 \\
\hline Other Services & 0.00 & 3.16 \\
\hline All & 0.20 & 6.73 \\
\hline
\end{tabular}

Notes: Cost is the ratio of realized price adjustment costs to revenue and the kurtosis is that of the distribution of percental price changes. These statistics were computed using a sample of 1500 simulated observations from the model with heterogeneous price rigidity. 
Table 7. Shock Processes

\begin{tabular}{|c|c|c|c|c|}
\hline \multirow[b]{2}{*}{ Description } & \multicolumn{2}{|c|}{$\begin{array}{c}\text { Heterogenous } \\
\text { Rigidity }\end{array}$} & \multicolumn{2}{|c|}{$\begin{array}{l}\text { Identical } \\
\text { Rigidity }\end{array}$} \\
\hline & Estimate & s.e & Estimate & s.e. \\
\hline Capital adjustment parameter & 4.710 & 3.804 & 2.800 & 2.424 \\
\hline \multicolumn{5}{|l|}{ AR coefficient of productivity shock } \\
\hline Agriculture & 0.922 & 0.743 & $0.412^{*}$ & 0.208 \\
\hline All mining sectors & $0.827^{*}$ & 0.317 & $0.997^{*}$ & 0.320 \\
\hline Construction & 0.852 & 12.05 & $0.778^{*}$ & 0.196 \\
\hline All manufacturing sectors & $0.949^{*}$ & 0.210 & $0.998^{*}$ & 0.047 \\
\hline All service sectors & 0.763 & 4.200 & $0.999^{*}$ & 0.026 \\
\hline \multicolumn{5}{|l|}{ SD of productivity innovation } \\
\hline Agriculture & $0.111^{*}$ & 0.018 & $0.232^{*}$ & 0.031 \\
\hline All mining sectors & 0.063 & 0.049 & $0.024^{*}$ & 0.008 \\
\hline Construction & 0.024 & 0.692 & 0.177 & 0.112 \\
\hline All manufacturing sectors & 0.033 & 0.031 & 0.019 & 0.013 \\
\hline All service sectors & 0.020 & 0.058 & 0.003 & 0.045 \\
\hline AR coefficient of labor supply shock & $0.984^{*}$ & 0.092 & $0.999^{*}$ & 0.097 \\
\hline SD of labor supply innovation & 0.012 & 0.018 & 0.001 & 0.040 \\
\hline AR coefficient of money demand shock & $0.711^{*}$ & 0.146 & 0.271 & 0.353 \\
\hline SD of money demand innovation & $0.186^{*}$ & 0.066 & $0.226^{*}$ & 0.040 \\
\hline AR coefficient of monetary policy shock & $0.456^{*}$ & 0.068 & $0.267^{*}$ & 0.076 \\
\hline SD of monetary policy innovation & $0.008^{*}$ & 0.001 & $0.008^{*}$ & 0.001 \\
\hline
\end{tabular}

Note: $*$ denotes significance at the 5 percent level. 
Table 8. Understanding Sectoral Responses to a Monetary Policy Shock

\begin{tabular}{|c|c|c|}
\hline $\begin{array}{c}\text { Sectoral } \\
\text { Characteristic }\end{array}$ & $\begin{array}{l}\text { Sectoral } \\
\text { Inflation }\end{array}$ & $\begin{array}{l}\text { Sectoral } \\
\text { Output }\end{array}$ \\
\hline & \multicolumn{2}{|c|}{ A. Correlations } \\
\hline Price rigidity & $-0.80^{*}$ & $0.37^{*}$ \\
\hline Durability & -0.06 & $0.65^{*}$ \\
\hline Labor intensity & 0.00 & 0.29 \\
\hline Material intensity & $-0.37^{*}$ & 0.23 \\
\hline Flexible-price inputs & $0.65^{*}$ & $-0.49^{*}$ \\
\hline \multirow[t]{2}{*}{ SD of productivity shock } & 0.03 & -0.23 \\
\hline & \multicolumn{2}{|c|}{ B. OLS } \\
\hline Intercept & $\begin{array}{c}2.940 \\
(1.447)\end{array}$ & $\begin{array}{l}-0.306 \\
(2.131)\end{array}$ \\
\hline Price rigidity & $\begin{array}{c}-0.221^{*} \\
(0.053)\end{array}$ & $\begin{array}{c}0.063 \\
(0.076)\end{array}$ \\
\hline Durability & $\begin{array}{c}0.098 \\
(0.253)\end{array}$ & $\begin{array}{l}1.322^{*} \\
(0.436)\end{array}$ \\
\hline Labor intensity & $\begin{array}{l}-0.940 \\
(1.620)\end{array}$ & $\begin{array}{c}4.316 \\
(2.218)\end{array}$ \\
\hline Material intensity & $\begin{array}{l}-1.879 \\
(1.236)\end{array}$ & $\begin{array}{c}3.939^{*} \\
(1.581)\end{array}$ \\
\hline Flexible-price inputs & $\begin{array}{c}0.814 \\
(0.693)\end{array}$ & $\begin{array}{l}-0.990 \\
(1.497)\end{array}$ \\
\hline SD of productivity shock & $\begin{array}{c}1.029 \\
(2.815)\end{array}$ & $\begin{array}{l}-7.412 \\
(4.650)\end{array}$ \\
\hline R-squared & 0.707 & 0.654 \\
\hline
\end{tabular}

Notes: * denotes significance at the 5 percent level. White heteroskedasticity-consistent standard errors are reported in parenthesis. 
Table 9. Aggregate Persistence and Volatility

\begin{tabular}{|c|c|c|c|c|}
\hline & \multicolumn{2}{|c|}{ Persistence } & \multicolumn{2}{|c|}{ Volatility } \\
\hline & $\begin{array}{l}\text { Aggregate } \\
\text { Inflation }\end{array}$ & $\begin{array}{c}\text { Aggregate } \\
\text { Output }\end{array}$ & $\begin{array}{l}\text { Aggregate } \\
\text { Inflation }\end{array}$ & $\begin{array}{c}\text { Aggregate } \\
\text { Output }\end{array}$ \\
\hline & \multicolumn{4}{|c|}{ A. Heterogeneous Rigidity } \\
\hline Aggregate & 0.51 & 0.95 & 0.77 & 4.62 \\
\hline Median Sector & 0.21 & 0.93 & 1.65 & 5.46 \\
\hline & \multicolumn{4}{|c|}{ B. Identical Rigidity } \\
\hline Aggregate & 0.25 & 0.95 & 0.85 & 4.04 \\
\hline \multirow[t]{2}{*}{ Median Sector } & 0.25 & 0.98 & 1.03 & 7.49 \\
\hline & \multicolumn{4}{|c|}{ C. U.S. Data } \\
\hline Aggregate & 0.71 & 0.94 & 0.78 & 3.20 \\
\hline
\end{tabular}


Table 10. Variance Decomposition

\begin{tabular}{lcclcc}
\hline \hline & \multicolumn{2}{c}{$\begin{array}{c}\text { Heterogeneous } \\
\text { Rigidity }\end{array}$} & & \multicolumn{2}{c}{$\begin{array}{c}\text { Identical } \\
\text { Rigidity }\end{array}$} \\
\cline { 2 - 3 } \cline { 5 - 6 } \multicolumn{1}{c}{ Shock } & $\begin{array}{c}\text { Aggregate } \\
\text { Inflation }\end{array}$ & $\begin{array}{c}\text { Aggregate } \\
\text { Output }\end{array}$ & & $\begin{array}{c}\text { Aggregate } \\
\text { Inflation }\end{array}$ & $\begin{array}{c}\text { Aggregate } \\
\text { Output }\end{array}$ \\
\hline \multirow{2}{*}{ All Productivity } & 5.19 & 5.73 & & 12.14 & 90.35 \\
Labor Supply & 6.70 & 64.31 & & 0.04 & 3.01 \\
Money Demand & 16.20 & 6.18 & & 9.57 & 1.97 \\
Monetary Policy & 71.91 & 23.78 & & 78.25 & 4.67 \\
& & & & & \\
\hline
\end{tabular}


Table 11. Sectoral Persistence and Volatility

\begin{tabular}{|c|c|c|c|c|}
\hline & \multicolumn{2}{|c|}{ Persistence } & \multicolumn{2}{|c|}{ Volatility } \\
\hline & $\begin{array}{l}\text { Sectoral } \\
\text { Inflation }\end{array}$ & $\begin{array}{c}\text { Sectoral } \\
\text { Output }\end{array}$ & $\begin{array}{l}\text { Sectoral } \\
\text { Inflation }\end{array}$ & $\begin{array}{l}\text { Sectoral } \\
\text { Output }\end{array}$ \\
\hline \multicolumn{5}{|l|}{ Sector } \\
\hline Agriculture & -0.06 & 0.94 & 4.60 & 10.16 \\
\hline Metal Mining & 0.13 & 0.93 & 2.24 & 5.08 \\
\hline Coal Mining & 0.08 & 0.93 & 3.05 & 6.45 \\
\hline Oil and Gas Extraction & -0.10 & 0.95 & 2.51 & 4.13 \\
\hline Nonmetallic Mining & 0.59 & 0.92 & 0.85 & 4.79 \\
\hline Construction & 0.70 & 0.84 & 0.61 & 9.66 \\
\hline Food Products & 0.79 & 0.95 & 0.54 & 5.12 \\
\hline Tobacco Products & -0.08 & 0.97 & 2.02 & 3.77 \\
\hline Textile Mill Products & 0.49 & 0.92 & 1.14 & 5.35 \\
\hline Apparel & 0.90 & 0.95 & 0.40 & 5.05 \\
\hline Lumber and Wood & 0.66 & 0.83 & 0.79 & 7.55 \\
\hline Furniture and Fixtures & 0.78 & 0.91 & 0.60 & 5.43 \\
\hline Paper & 0.07 & 0.94 & 1.77 & 4.88 \\
\hline Printing and Publishing & 0.48 & 0.94 & 1.20 & 6.39 \\
\hline Chemicals & -0.08 & 0.96 & 2.36 & 5.05 \\
\hline Oil Refining & 0.09 & 0.95 & 1.73 & 3.54 \\
\hline Rubber and Plastics & 0.20 & 0.92 & 1.75 & 5.64 \\
\hline Leather & 0.86 & 0.95 & 0.46 & 5.62 \\
\hline Stone, Clay and Glass & 0.42 & 0.88 & 1.26 & 6.70 \\
\hline Primary Metal & 0.89 & 0.88 & 0.36 & 8.12 \\
\hline Fabricated Metal & -0.11 & 0.94 & 2.39 & 7.26 \\
\hline Nonelectric Machinery & -0.11 & 0.93 & 2.59 & 7.83 \\
\hline Electric Machinery & -0.09 & 0.95 & 2.79 & 7.10 \\
\hline Transportation Equip. & 0.58 & 0.90 & 0.87 & 7.01 \\
\hline Instruments & -0.09 & 0.91 & 2.95 & 6.76 \\
\hline Misc. Manufacturing & 0.22 & 0.93 & 1.58 & 5.49 \\
\hline Transport and Utilities & 0.73 & 0.93 & 0.58 & 4.96 \\
\hline Trade & 0.84 & 0.94 & 0.43 & 5.30 \\
\hline FIRE & -0.16 & 0.96 & 3.55 & 4.38 \\
\hline Other Services & -0.09 & 0.93 & 3.22 & 5.02 \\
\hline
\end{tabular}


Table 12. Understanding Sectoral Persistence and Volatility

\begin{tabular}{|c|c|c|c|c|}
\hline \multirow{3}{*}{$\begin{array}{c}\text { Sectoral } \\
\text { Characteristic }\end{array}$} & \multicolumn{2}{|c|}{ Persistence } & \multicolumn{2}{|c|}{ Volatility } \\
\hline & Sectoral & Sectoral & Sectoral & Sectoral \\
\hline & Inflation & Output & Inflation & Output \\
\hline & \multicolumn{4}{|c|}{ A. Correlations } \\
\hline Price rigidity & $0.89^{*}$ & -0.22 & $-0.76^{*}$ & 0.06 \\
\hline Durability & 0.07 & $-0.61^{*}$ & -0.13 & $0.58^{*}$ \\
\hline Labor intensity & 0.08 & -0.21 & 0.05 & 0.32 \\
\hline Material intensity & 0.29 & -0.14 & -0.35 & 0.13 \\
\hline Flexible-price inputs & $-0.68^{*}$ & $0.38^{*}$ & $0.60^{*}$ & -0.24 \\
\hline \multirow[t]{2}{*}{ SD of productivity shock } & -0.20 & 0.09 & $0.37^{*}$ & $0.41^{*}$ \\
\hline & \multicolumn{4}{|c|}{ B. OLS } \\
\hline \multirow[t]{2}{*}{ Intercept } & -0.093 & $0.940^{*}$ & 1.928 & -0.698 \\
\hline & $(0.371)$ & $(0.068)$ & $(1.758)$ & $(2.699)$ \\
\hline \multirow[t]{2}{*}{ Price rigidity } & $0.100^{*}$ & -0.001 & $-0.213^{*}$ & 0.085 \\
\hline & $(0.019)$ & $(0.002)$ & $(0.059)$ & $(0.094)$ \\
\hline \multirow[t]{2}{*}{ Durability } & -0.026 & $-0.035^{*}$ & -0.106 & $1.530^{*}$ \\
\hline & $(0.082)$ & $(0.013)$ & $(0.279)$ & $(0.520)$ \\
\hline \multirow[t]{2}{*}{ Labor intensity } & 0.333 & -0.027 & 0.779 & $7.489^{*}$ \\
\hline & $(0.396)$ & $(0.062)$ & $(2.081)$ & $(2.498)$ \\
\hline \multirow[t]{2}{*}{ Material intensity } & 0.550 & -0.017 & -2.434 & 2.176 \\
\hline & $(0.312)$ & $(0.048)$ & $(1.561)$ & $(2.097)$ \\
\hline \multirow[t]{2}{*}{ Flexible-price inputs } & -0.358 & 0.024 & 1.052 & 0.899 \\
\hline & $(0.276)$ & $(0.049)$ & $(0.687)$ & $(1.687)$ \\
\hline \multirow[t]{2}{*}{ SD of productivity shock } & 0.741 & 0.052 & $9.183^{*}$ & $18.364^{*}$ \\
\hline & $(0.542)$ & $(0.090)$ & $(4.267)$ & $(7.674)$ \\
\hline R-squared & 0.831 & 0.435 & 0.741 & 0.630 \\
\hline
\end{tabular}

Notes: * denotes significance at the 5 percent level. White heteroskedasticity-consistent standard errors are reported in parenthesis. 
Table 13. Fraction (in \%) of Unconditional Variance Accounted for by Own Productivity Shock

\begin{tabular}{lcccc}
\hline \hline & & Sectoral & Sectoral & \\
\multicolumn{1}{c}{ Sector } & Sectoral & Relative & Marginal & Sectoral \\
& Inflation & Price & Cost & Output \\
\hline & & & & \\
Agriculture & 82.4 & 96.4 & 98.4 & 79.4 \\
Metal Mining & 63.2 & 86.5 & 82.9 & 40.3 \\
Coal Mining & 68.7 & 86.6 & 84.6 & 53.0 \\
Oil and Gas Extraction & 8.8 & 30.9 & 30.7 & 35.2 \\
Nonmetallic Mining & 42.5 & 83.3 & 73.1 & 13.8 \\
Construction & 7.2 & 48.4 & 21.5 & 2.8 \\
Food Products & 8.1 & 32.6 & 24.6 & 6.6 \\
Tobacco Products & 7.9 & 42.2 & 42.2 & 13.2 \\
Textile Mill Products & 29.3 & 85.9 & 77.4 & 23.2 \\
Apparel & 17.7 & 52.9 & 74.7 & 13.4 \\
Lumber and Wood & 24.9 & 94.5 & 68.5 & 12.0 \\
Furniture and Fixtures & 30.8 & 90.6 & 80.3 & 20.3 \\
Paper & 29.6 & 81.4 & 78.8 & 34.5 \\
Printing and Publishing & 38.3 & 90.7 & 78.2 & 40.0 \\
Chemicals & 20.9 & 70.1 & 69.4 & 34.0 \\
Oil Refining & 2.7 & 16.9 & 14.9 & 4.9 \\
Rubber and Plastics & 24.3 & 76.8 & 68.8 & 28.5 \\
Leather & 29.5 & 82.3 & 90.0 & 20.0 \\
Stone, Clay and Glass & 32.5 & 90.1 & 73.6 & 27.2 \\
Primary Metal & 16.2 & 53.5 & 75.2 & 4.6 \\
Fabricated Metal & 27.3 & 79.6 & 79.6 & 29.1 \\
Nonelectric Machinery & 15.9 & 71.2 & 71.2 & 47.6 \\
Electric Machinery & 22.9 & 74.0 & 74.0 & 40.8 \\
Transportation Equip. & 26.6 & 92.2 & 71.0 & 20.2 \\
Instruments & 24.7 & 76.1 & 76.1 & 45.0 \\
Misc. Manufacturing & 31.1 & 86.9 & 80.7 & 33.7 \\
Transport and Utilities & 4.7 & 16.9 & 17.3 & 0.6 \\
Trade & 4.2 & 5.7 & 27.0 & 0.6 \\
FIRE & 4.7 & 7.7 & 7.7 & 4.6 \\
Other Services & 11.2 & 16.9 & 16.7 & 7.0 \\
& & & & \\
\hline
\end{tabular}




\section{References}

[1] Altissimo, F., Mojon, B., and Zaffaroni, P., (2007), "Fast Micro and Slow Macro: Can Aggregation Explain the Persistence of Inflation," Federal Reserve Bank of Chicago, Working Paper 07-02.

[2] Aoki, K., (2001), "Optimal Monetary Policy Responses to Relative Price Changes," Journal of Monetary Economics 48, pp. 55-80.

[3] Barth, M. J., and Ramey, V. A., (2001), "The Cost Channel of Monetary Transmission," NBER Macroeconomics Annual 16, pp. 199-239.

[4] Barsky, R. B., House, C. and Kimball, M. S., (2007), "Sticky-Price Models and Durable Goods," American Economic Review 97, pp. 984-998.

[5] Basu, S., (1995), "Intermediate Goods and Business Cycles: Implications for Productivity and Welfare," American Economic Review 85, pp. 512-31.

[6] Benigno, P., (2004), "Optimal Monetary Policy in a Currency Area," Journal of International Economics 63, pp. 293-320.

[7] Bils, M. and Klenow, P. J., (2004), "Some Evidence on the Importance of Sticky Prices," Journal of Political Economy 112, pp. 947-985.

[8] Blanchard, O. J. and Khan, C. M., (1980), "The Solution of Linear Difference Models Under Rational Expectations," Econometrica 48, pp. 1305-1311.

[9] Boivin, J., Giannoni, M. P., and Mihov, I., (2007), "Sticky Prices and Monetary Policy: Evidence from Disaggregated Data," American Economic Review, forthcoming.

[10] Bouakez, H., Cardia, E., and Ruge-Murcia, F. J., (2005), "Habit Formation and the Persistence of Monetary Shocks," Journal of Monetary Economics 52, pp. 1073-1088.

[11] Bouakez, H., Cardia, E., and Ruge-Murcia, F. J., (2008), "The Transmission of Monetary Policy in a Multi-Sector Economy," International Economic Review, forthcoming.

[12] Bouakez , H., and Rebei, N., (2008), "Has Exchange Rate Pass-Through Really Declined? Evidence from Canada," Journal of International Economics 75, pp. 249-267.

[13] Carlton, D. W., (1986), "The Rigidity of Prices," American Economic Review 76, pp. 637-658. 
[14] Carvalho, C., (2006), "Heterogeneity in Price Stickiness and the Real Effects of Monetary Shocks," Frontiers of Macroeconomics 2, Article 1.

[15] Carvalho, C. and Dam, N. A., (2008), "Estimating the Cross-sectional Distribution of Price Stickiness from Aggregate Data," Federal Reserve Bank of New York, Mimeo.

[16] Carvalho, V., (2008), "Aggregate Fluctuations and the Network Structure of Intersectoral Trade," Universitat Pompeu Fabra, Mimeo.

[17] Christiano, L. J., Eichenbaum, M., and Evans, C. L., (2005), "Nominal Rigidities and the Dynamic Effects of a Shock to Monetary Policy," Journal of Political Economy 113, pp. 1-45.

[18] Clark, T. E., (2006), "Disaggregate Evidence on the Persistence of Consumer Price Inflation," Journal of Applied Econometrics 21, pp. 563-587.

[19] Coenen, G. and A. Levin, (2004), "Identifying the Influences of Nominal and Real Rigidities in Aggregate Price-Setting Behavior," ECB Working Paper No. 418.

[20] Coenen, G. and V. Wieland, (2005), "A Small Estimated Euro Area Model with Rational Expectations and Nominal Rigidities," European Economic Review, 49, pp. 1081-1104.

[21] Cooper, R. W. and Haltiwanger, J., (2006), "On the Nature of Capital Adjustment Costs," Review of Economic Studies 473, pp. 611-633.

[22] Davis, S. J. and Haltiwanger, J., (1991), "Wage Dispersion Between and Within U.S. Manufacturing Plants, 1963-1986," NBER Working Paper No. 3722.

[23] Dedola, L. and Lippi, F., (2005), "The Monetary Transmission Mechanism: Evidence from the Industries of Five OECD Countries," European Economic Review 49, pp. 1543-1569.

[24] Duffie, D. and Singleton, K. J., (1993), "Simulated Moments Estimation of Markov Models of Asset Prices," Econometrica 61, pp. 929-952.

[25] Dupor, W. D., (1999), "Aggregation and Irrelevance in Multi-Sector Models," Journal of Monetary Economics 43, pp. 391-409.

[26] Eichenbaum, M., Jaimovich, N., and Rebelo, S., (2008), "Reference Prices and Nominal Rigidities," Northwestern University, Mimeo.

[27] Erceg, C. J. and Levin, A., (2006), "Optimal Monetary Policy with Durable Consumption Goods," Journal of Monetary Economics 53, pp. 1341-1359. 
[28] Gagnon, E., (2007), "Price Setting During High and Low Inflation: Evidence from Mexico," International Finance Discussion Paper No. 896, Board of Governors of the Federal Reserve System.

[29] Gali, J. and Gertler, M., (1999), "Inflation Dynamics: A Structural Econometric Analysis," Journal of Monetary Economics 44, pp. 195-222.

[30] Gertler, M. and Leahy, J., (2008), "A Phillips Curve with an Ss Foundation," Journal of Political Economy 116, pp. 533-572.

[31] Golosov, M. and Lucas, R. E., (2007), "Menu Costs and Phillips Curves," Journal of Political Economy 115, pp. 171-199.

[32] Hall, R. E., (2004), "Measuring Factor Adjustment Costs," Quarterly Journal of Economics 119, pp. 899-927.

[33] Hogg, R. and Craig, A., (1978), Introduction to Mathematical Statistics, Macmillan Publishing: New York.

[34] Hornstein, A. and Praschnik, J., (1997), "Intermediate Inputs and Sectoral Comovements in the Business Cycle," Journal of Monetary Economics 40, pp. 573-598.

[35] Horvath, M., (2000), "Sectoral Shocks and Aggregate Fluctuations," Journal of Monetary Economics 45, pp. 69-106.

[36] Huang, K. and Liu Z., (2005), "Inflation Targeting: What Inflation Rate to Target?" Journal of Monetary Economics 52, pp. 1435-1462.

[37] Ireland, P., (2001), "Sticky-Price Models of the Business Cycle: Specification and Stability," Journal of Monetary Economics 47, pp. 3-18.

[38] Ireland, P., (2003), "Endogenous Money or Sticky Prices?," Journal of Monetary Economics 50, pp. 1623-1648.

[39] Jorgenson, D. W., and Fraumeni, B., (1987), Productivity and U.S. Economic Growth, Cambridge: Harvard University Press.

[40] Jorgenson, D. W., and Stiroh, K. J., (2000), "Rising the Speed Limit: U.S. Economic Growth in the Information Age," Brookings Papers on Economic Activity, pp. 125-235. 
[41] Kehoe, P. J. and Midrigan, V., (2007), "Sales and the Real Effects of Monetary Policy," Federal Reserve Bank of Minneapolis Working Paper No. 652.

[42] Kim, J., (2000), "Constructing and Estimating a Realistic Optimizing Model of Monetary Policy," Journal of Monetary Economics 45, pp. 329-359.

[43] Kim, J. and Ruge-Murcia F., (2007), "How Much Inflation is Necessary to Grease the Wheels?" CIREQ Working Paper 11-2007.

[44] Klein, P. and Jonsson, G. (1996), "Stochastic Fiscal Policy and the Swedish Business Cycle," Journal of Monetary Economics 38, pp. 245-68.

[45] Klenow, P. J. and Kryvtson, A., (2008), "State-Dependent Pricing or Time-Dependent Pricing: Does It Matter for Recent U.S. Inflation?" Quarterly Journal of Economics 123, pp. 863-904.

[46] Lee, B.-S., and Ingram, B. F., (1991), "Simulation Estimation of Time-Series Models," Journal of Econometrics 47, pp. 195-205.

[47] Levy, D., Bergen, M., Dutta, S., and Venable, R., (1997), "The Magnitude of Menu Costs: Direct Evidence from Large U.S. Supermarket Chains," Quarterly Journal of Economics 112, pp. $791-826$.

[48] Long, J. B. and Plosser, C. I., (1983), "Real Business Cycles," Journal of Political Economy 91, pp. 39-69.

[49] Long, J. B. and Plosser, C. I., (1987), "Sectoral vs. Aggregate Shocks in the Business Cycle," American Economic Review 77, pp. 333-336.

[50] Mackowiak, B., Moench, E., and Wiederholt, M., (2008), "Sectoral Price Data and Models of Price Setting," Northwestern University, Mimeo.

[51] Midrigan, V., (2008), "Menu Costs, Multi-Product Firms and Aggregate Fluctuations," New York University, Mimeo.

[52] Nakamura, E. and Steinsson, J., (2008a), "Five Facts About Prices: A Reevaluation of Menu Cost Models," Columbia University, Mimeo.

[53] Nakamura, E. and Steinsson, J., (2008b), "Monetary Non-Neutrality in a Multi-Sector Menu Cost Model," Columbia University, Mimeo. 
[54] Ng, S., and Perron, P., (2001), "Lag Length Selection and the Construction of Unit Root Tests with Good Size and Power," Econometrica 69, pp. 1519-1554.

[55] Ngai, L. R., and Pissarides, C. A., (2007), "Structural Change in a Multi-Sector Model of Growth," American Economic Review 97, pp. 429-443.

[56] Ohanian, L. E., Stockman, A. C., and Kilian, L., (1995), "The Effects of Real and Monetary Shocks in a Business Cycle Model with Some Sticky Prices," Journal of Money, Credit and Banking 27, pp. 1210-1234.

[57] Peersman, G. and F. Smets, (2005), "The Industry Effects of Monetary Policy in the Euro Area," Economic Journal 115, pp. 319-342.

[58] Rotemberg, J. J., (1982), "Sticky Prices in the United States," Journal of Political Economy 90, pp. 1187-1211.

[59] Ruge-Murcia, Francisco, J., (2007), "Methods to Estimate Dynamic Stochastic General Equilibrium Models," Journal of Economic Dynamics and Control 31, pp. 2599-2636.

[60] Shapiro, M., and Watson, M., (1988), "Sources of Business Cycle Fluctuations," NBER Macroeconomics Annual, S. Fished (ed.), pp. 111-148, Cambridge: MIT Press.

[61] Smets, F. and Wouters, R., (2003), "An Estimated Dynamic Stochastic General Equilibrium Model of the Euro Area," Journal of the European Economic Association 1, pp. 1123-1175.

[62] Zbaracki, M., M. Ritson, D. Levy, S. Dutta, and M. Bergen, (2004), "Managerial and Customer Costs of Price Adjustment: Direct Evidence from Industrial Markets," Review of Economics and Statistics 86, pp. 514-533. 
Figure 1: Distribution of Sectoral Price Rigidity

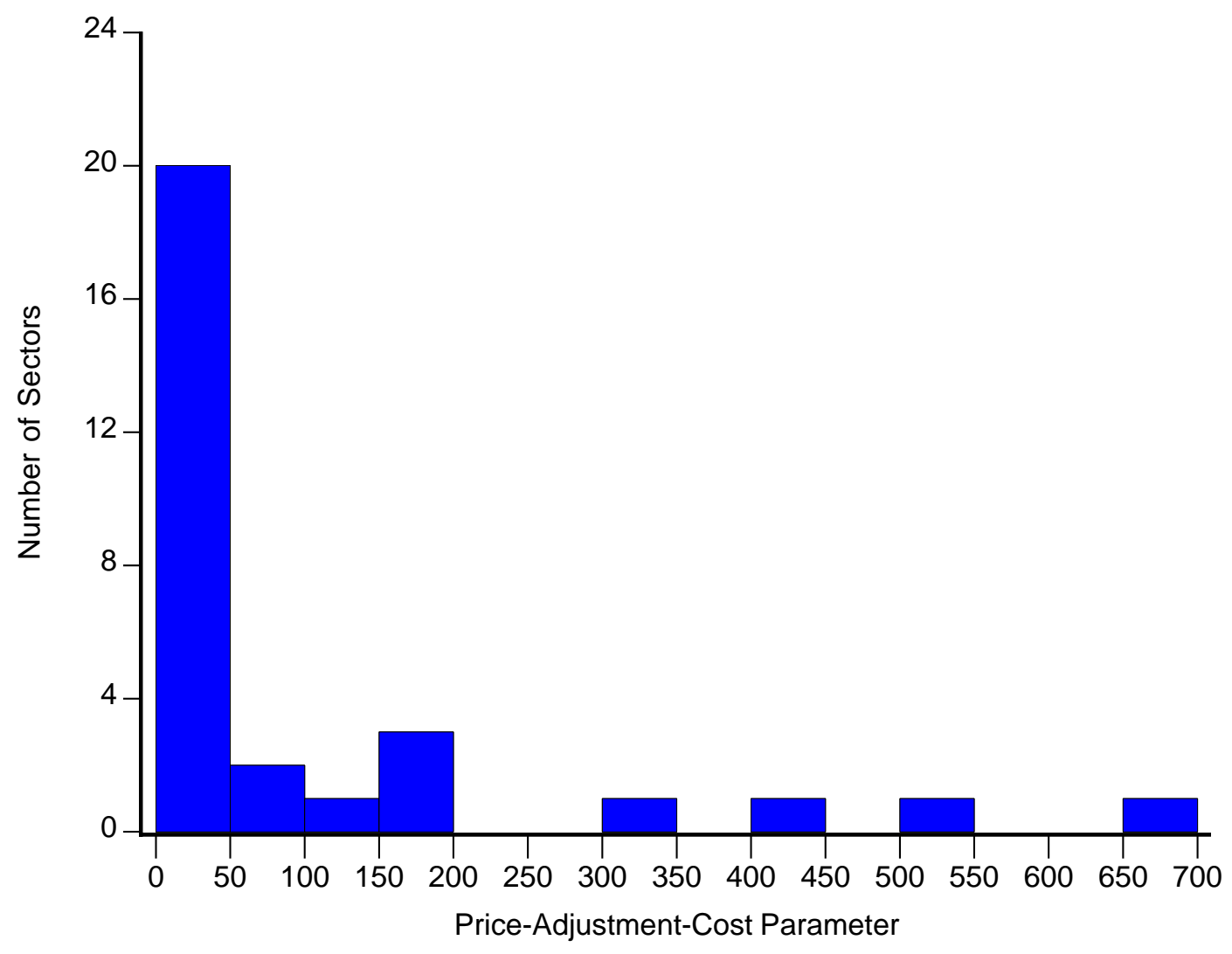


Figure 2: Comparison with Micro Estimates of Price Durations

A. PPI

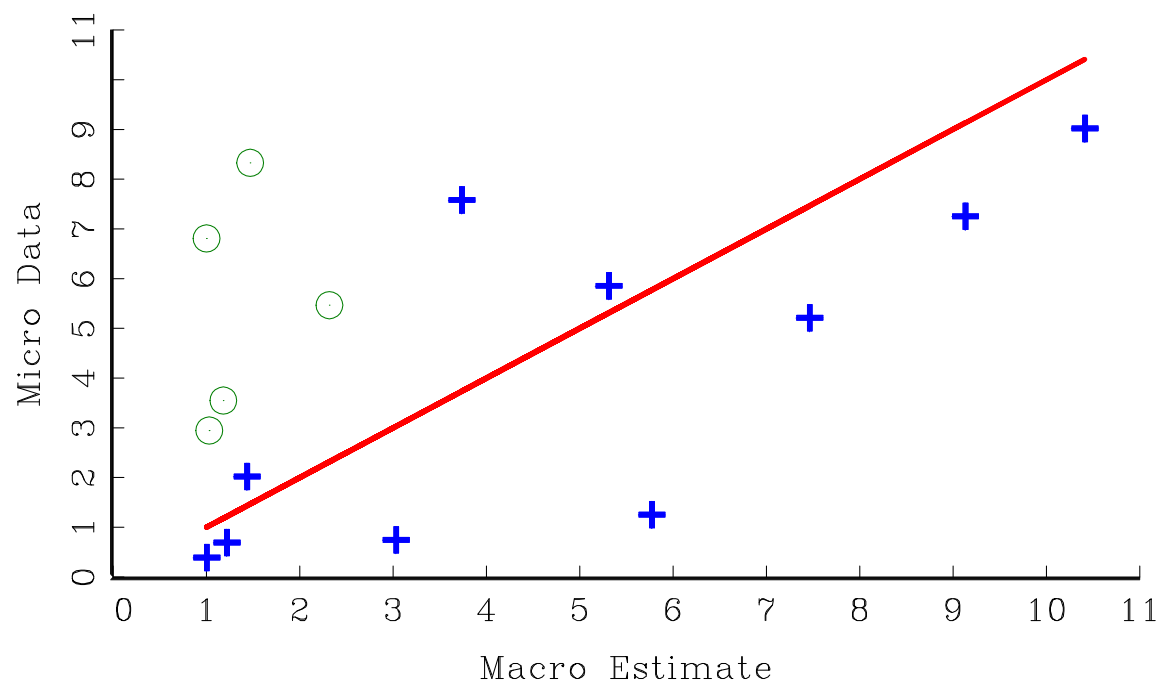

C. N\&S (Final Price)

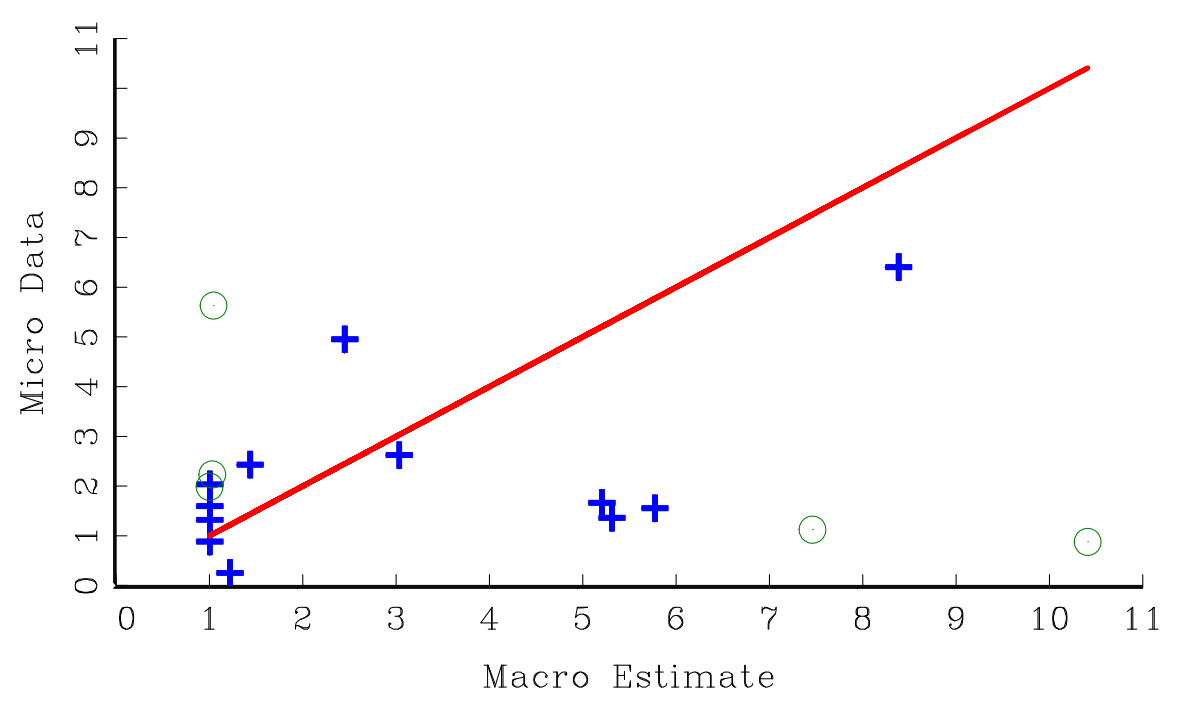

B. N\&S (Regular Price)

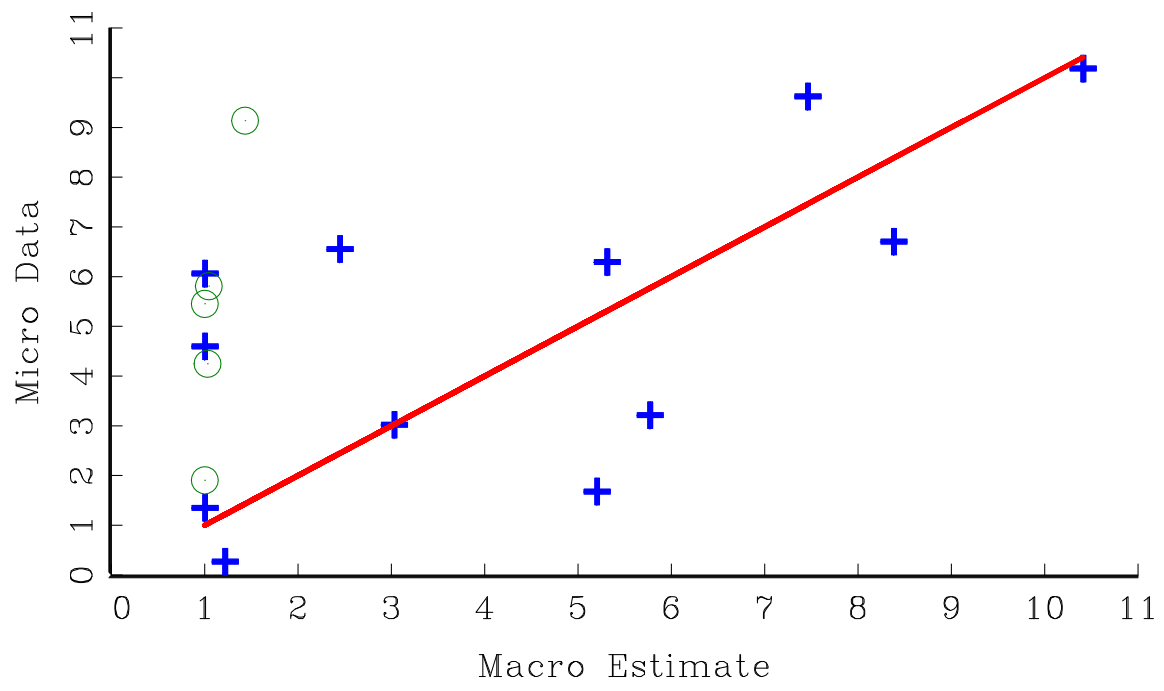

D. B\&K (Final Price)

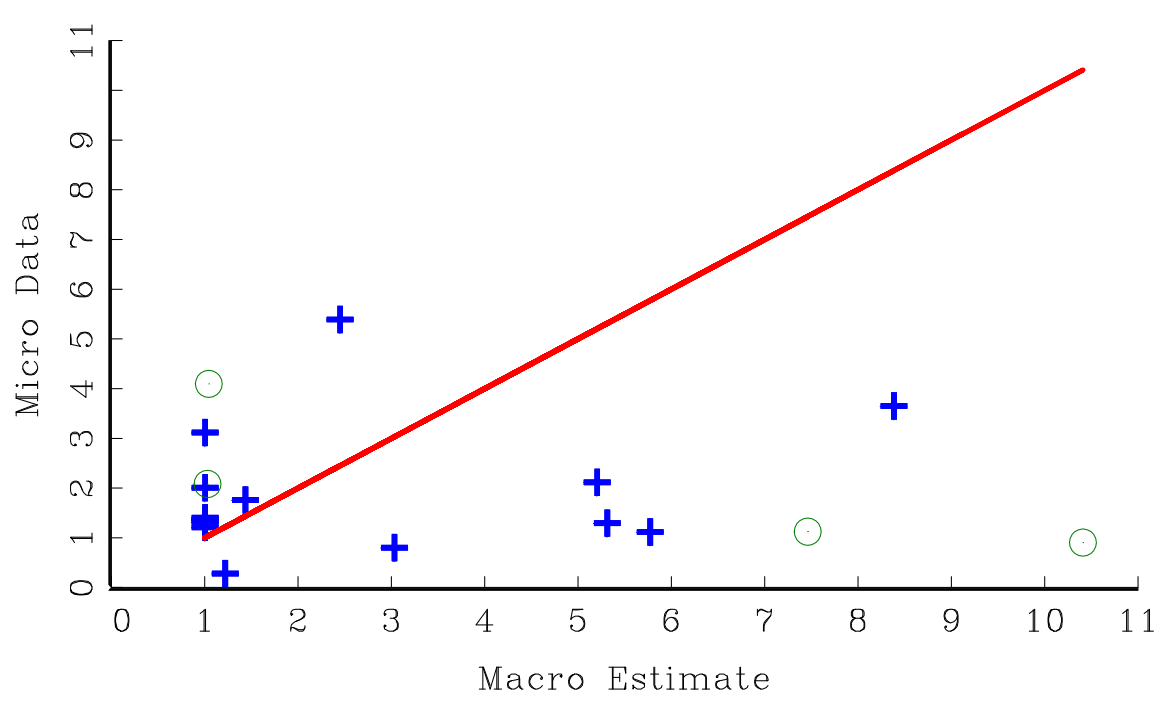


Figure 3: Comparison with Estimates Based on Solow Residuals

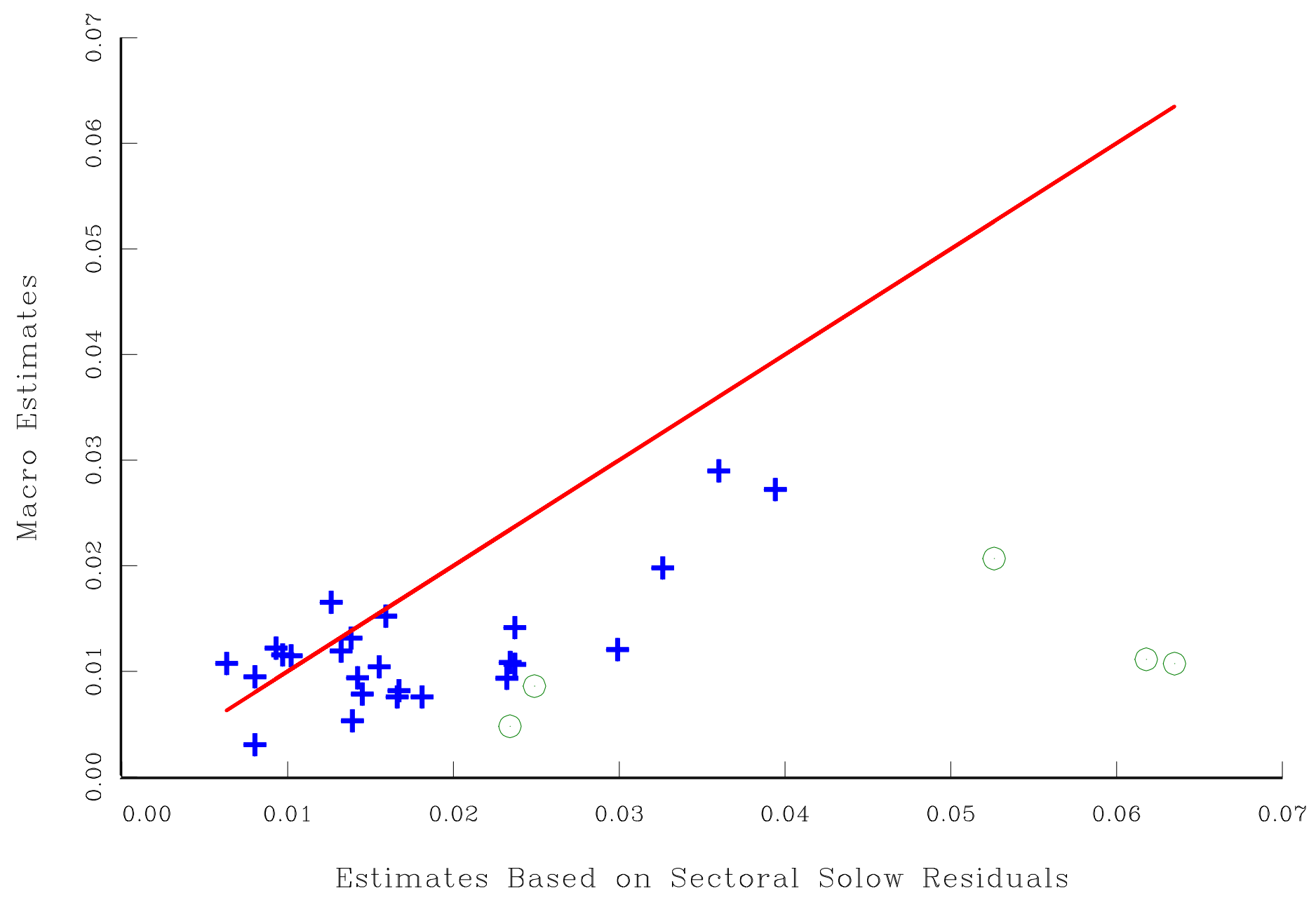


Figure 4: Sectoral Inflation Responses to a Monetary Policy Shock
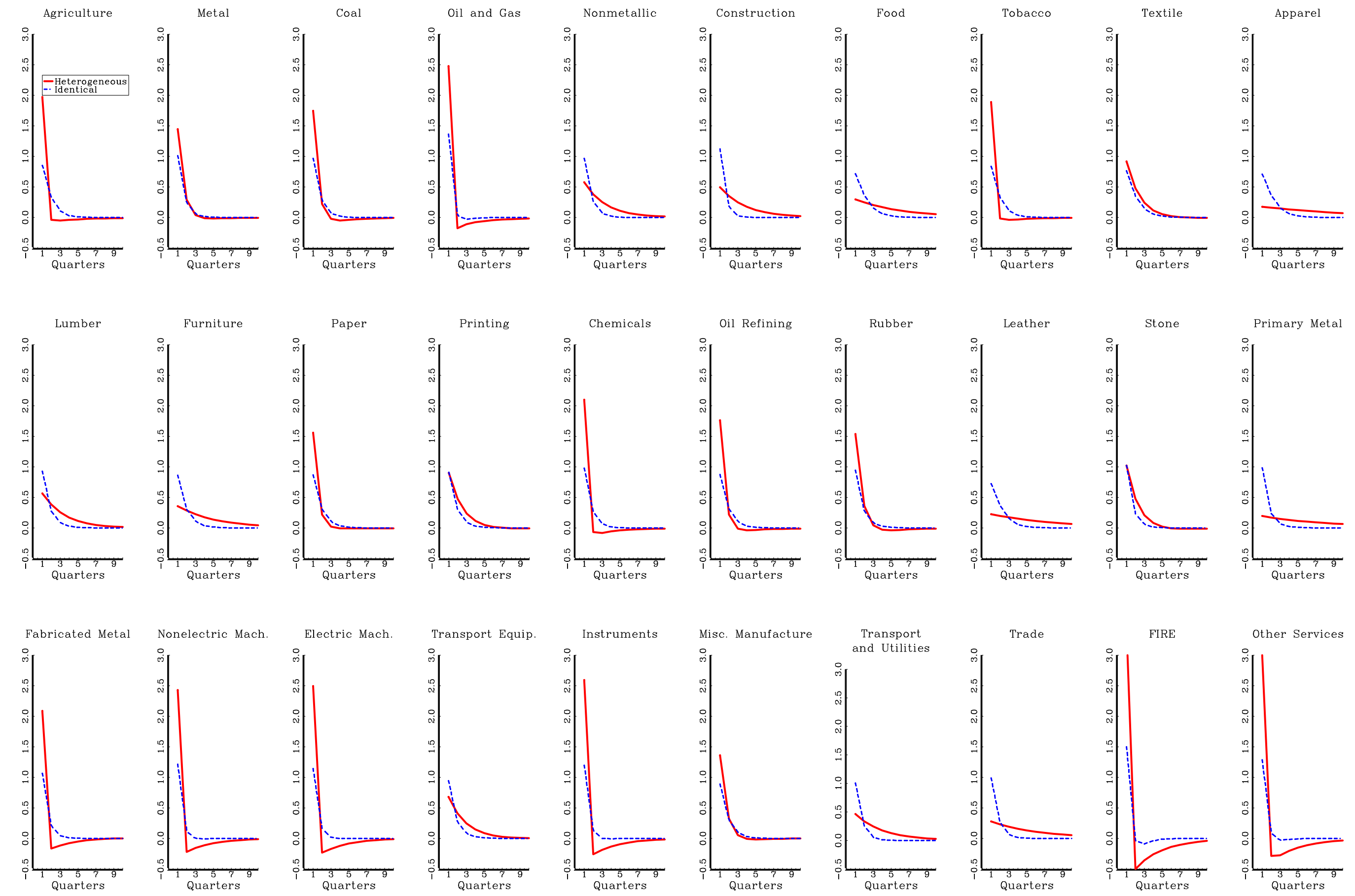
Figure 5: Changes in the Distribution of Relative Prices Following a Monetary Policy Shock

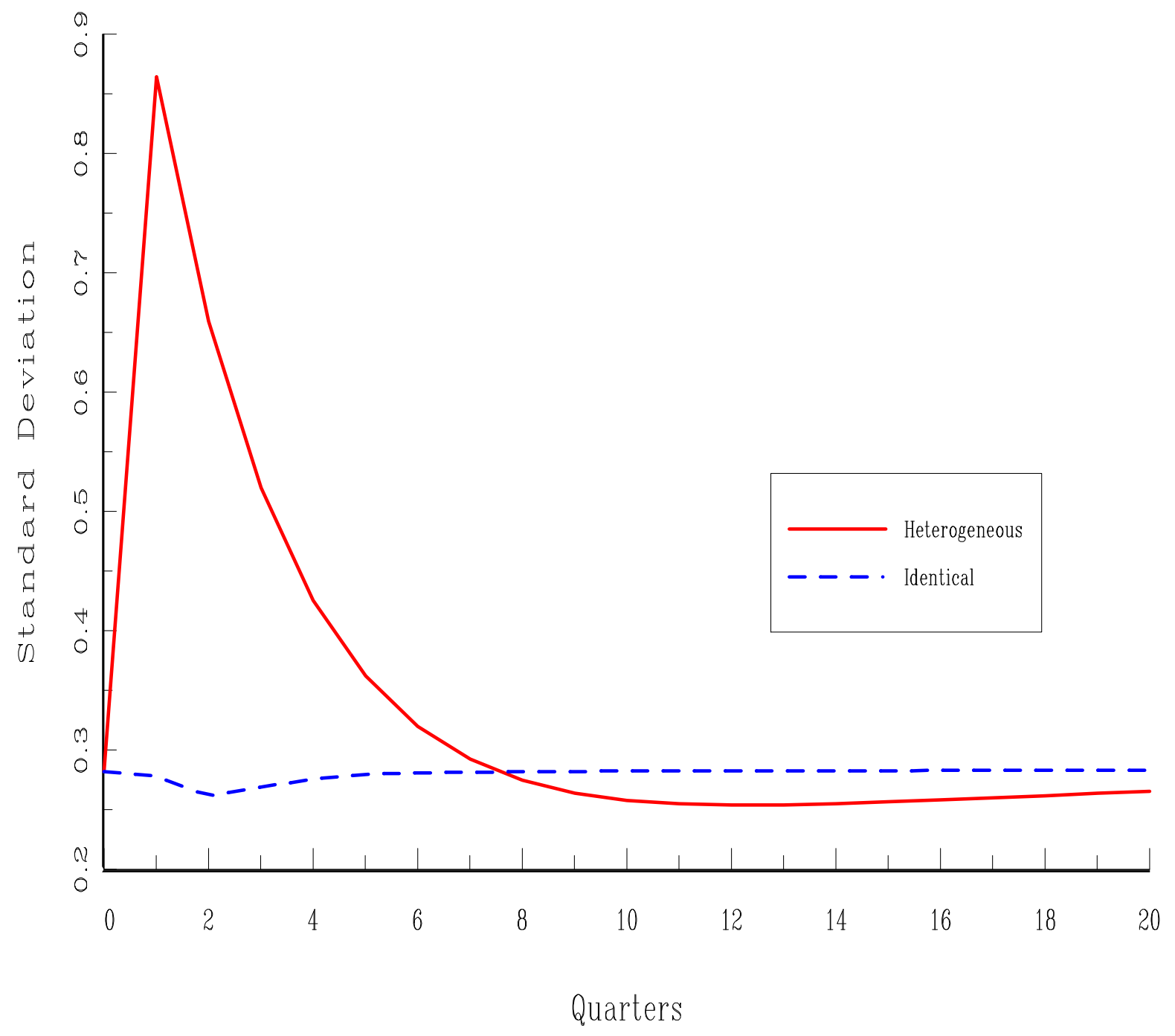


Figure 6: Sectoral Output Responses to a Monetary Policy Shock
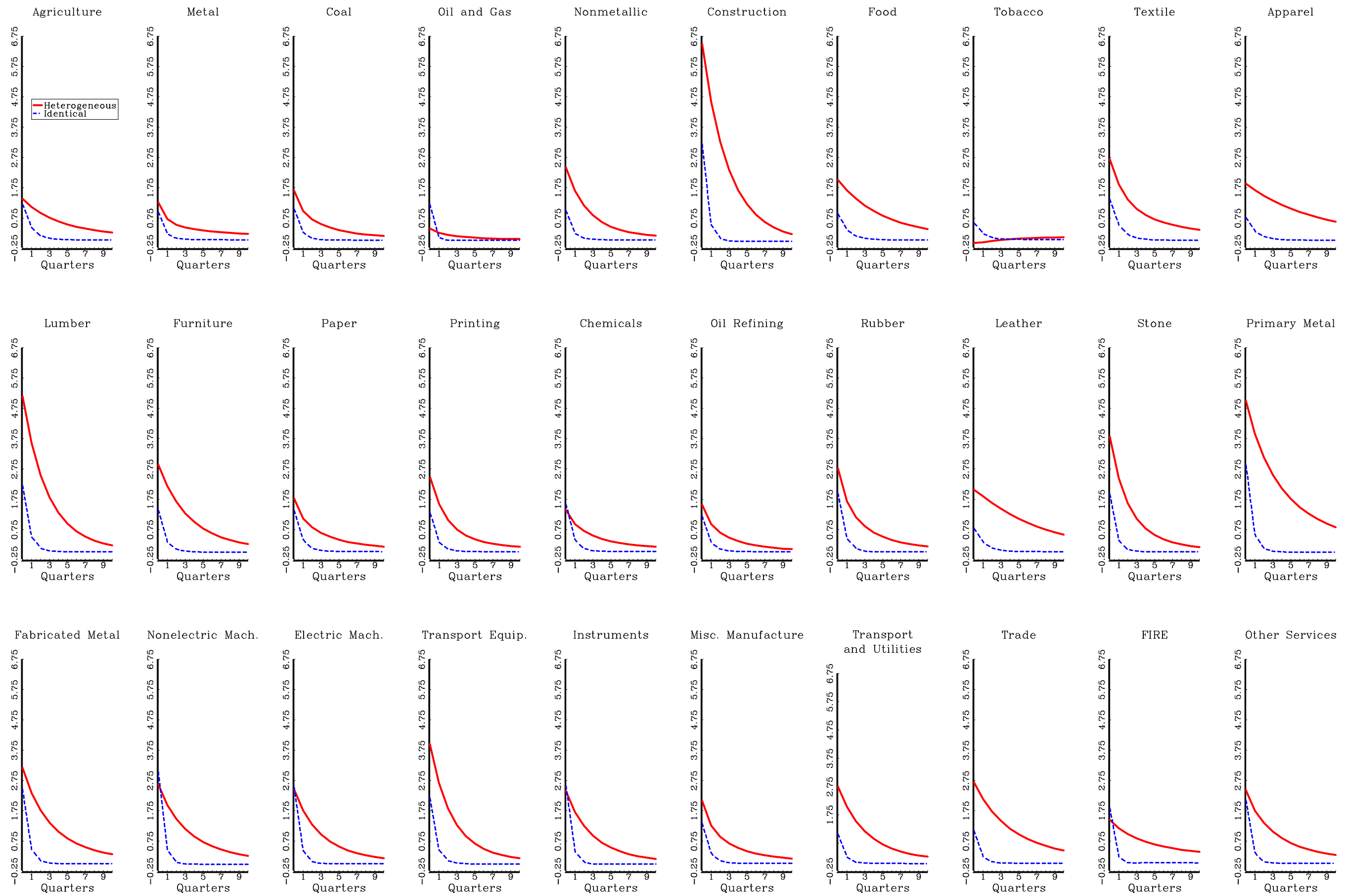
Figure 7: Responses of Aggregate Output and CPI Inflation to a Monetary Policy Shock
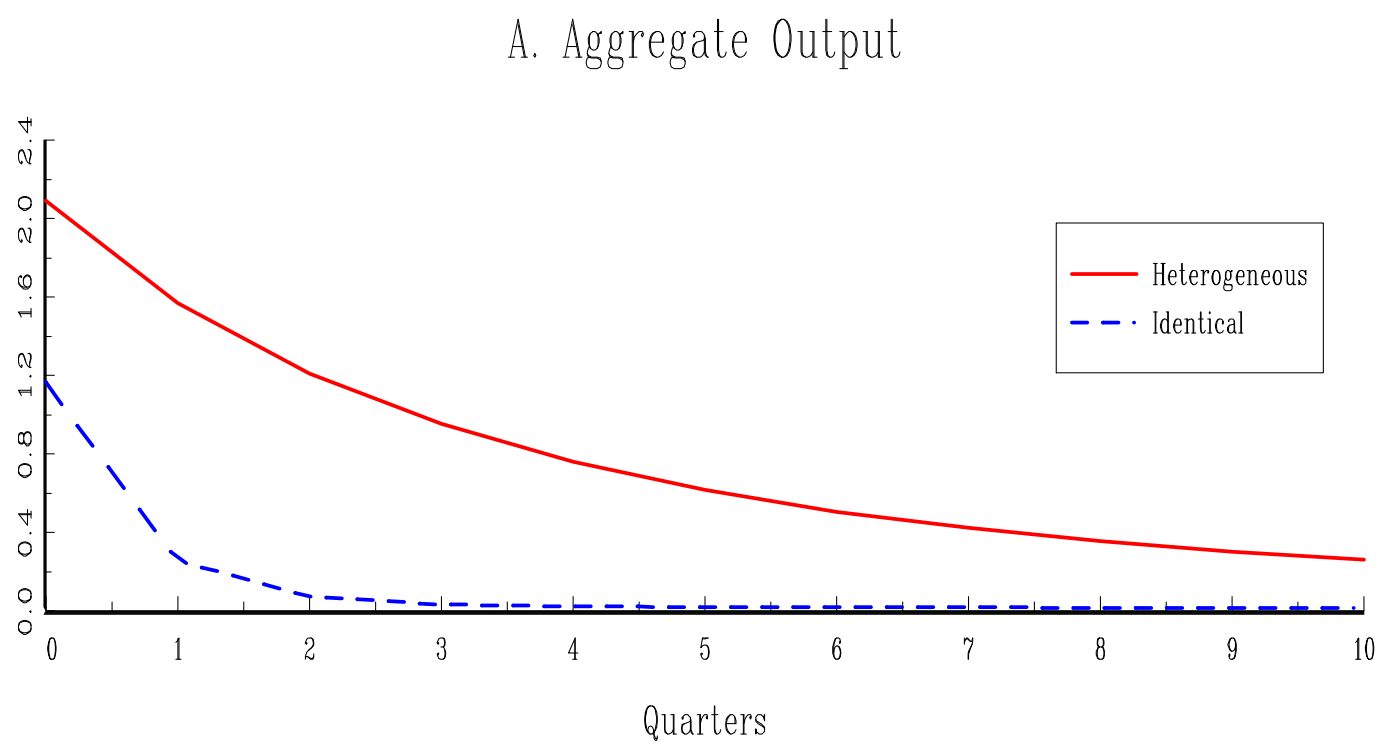

B. CPI Inflation

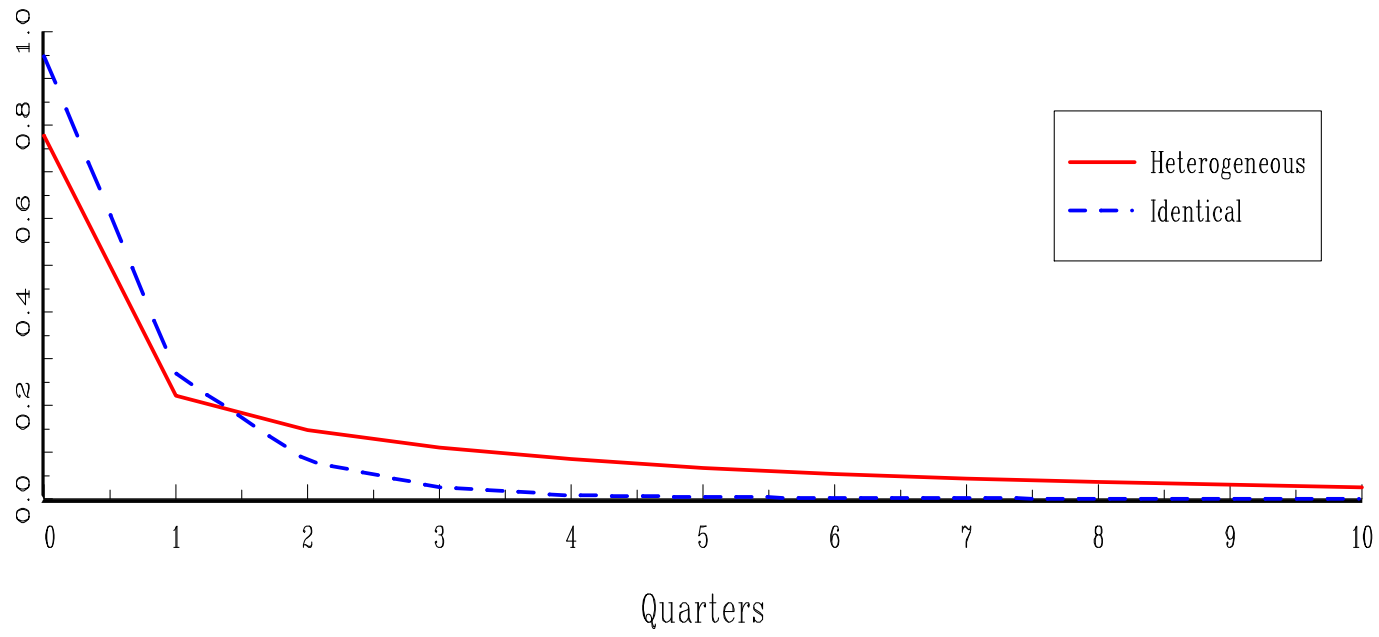


Figure 8: Pass-Through from Sectoral Marginal Costs to the CPI
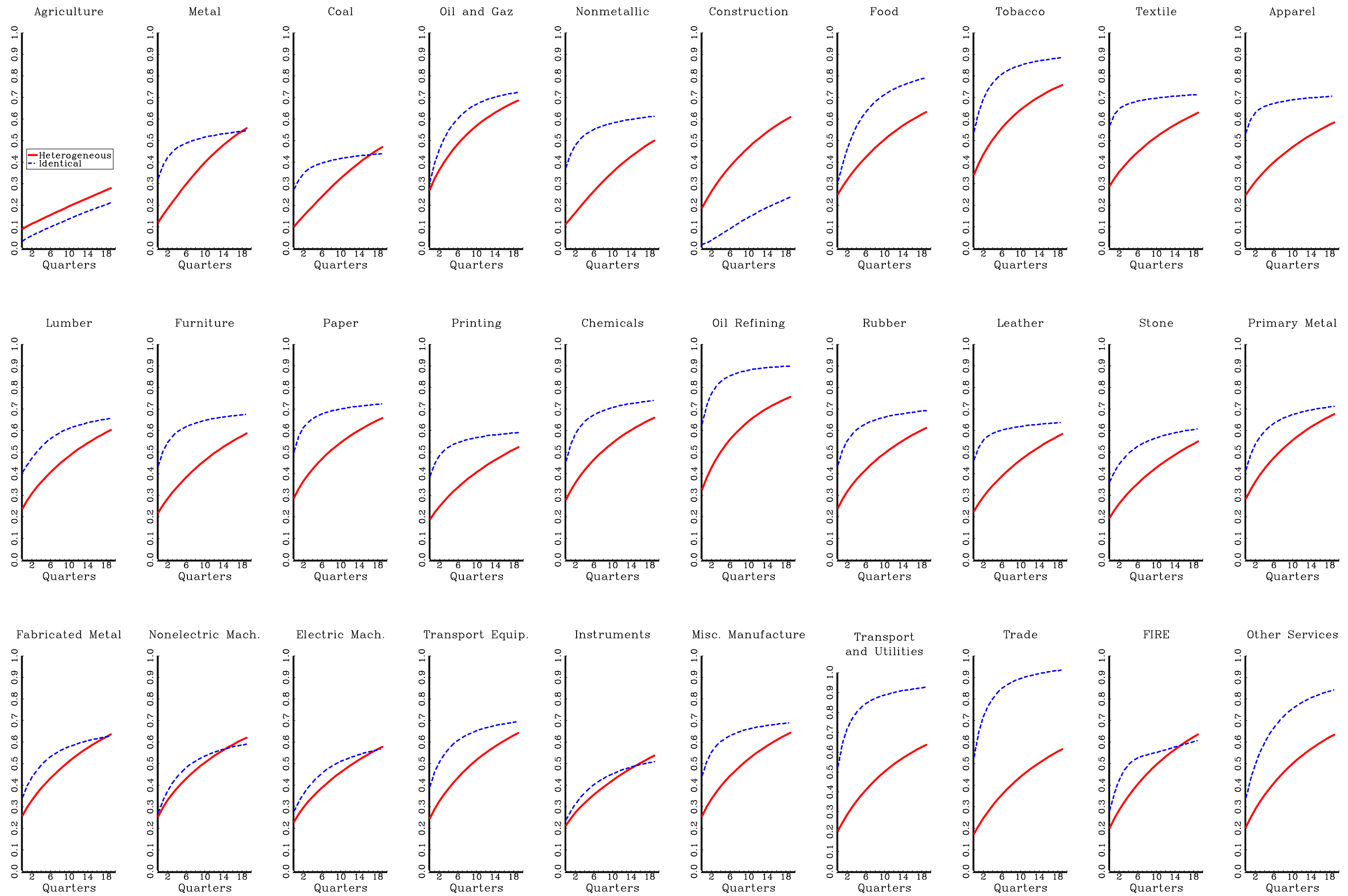
Figure 9: Cost Pass-Through to Sectoral Prices
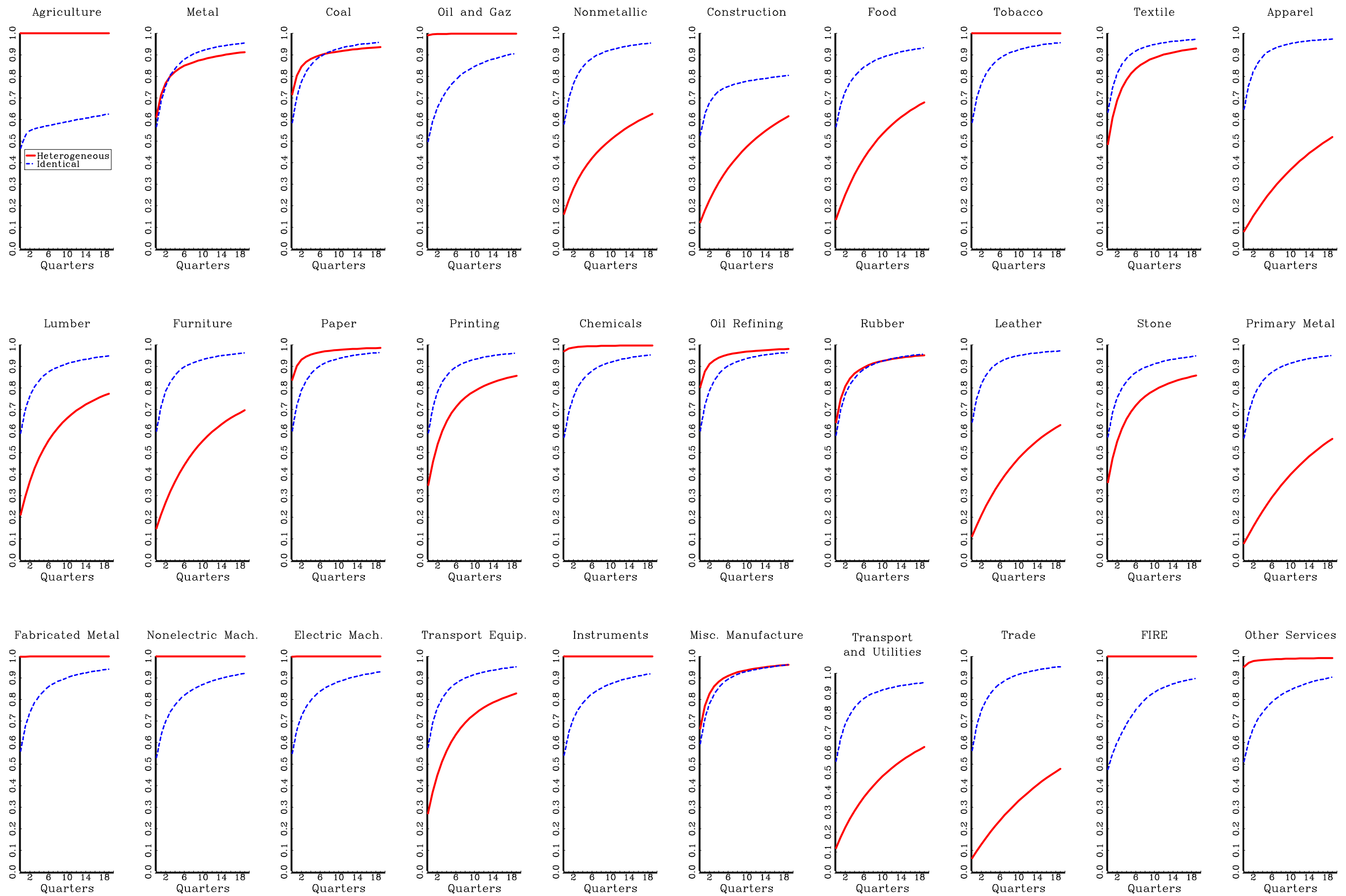

Quarters 